\title{
Review \\ Insight into the Photocatalytic Activity of Cobalt-Based Metal-Organic Frameworks and Their Composites
}

\author{
Aleksander Ejsmont (D), Agata Jankowska (D) and Joanna Goscianska * (D) \\ Department of Chemical Technology, Faculty of Chemistry, Adam Mickiewicz University in Poznań, \\ Uniwersytetu Poznańskiego 8, 61-614 Poznań, Poland; aleejs@amu.edu.pl (A.E.); agache1@amu.edu.pl (A.J.) \\ * Correspondence: joanna.goscianska@amu.edu.pl or asiagosc@amu.edu.pl
}

check for updates

Citation: Ejsmont, A.; Jankowska, A.; Goscianska, J. Insight into the Photocatalytic Activity of Cobalt-Based Metal-Organic Frameworks and Their Composites. Catalysts 2022, 12, 110. https:/ / doi.org/10.3390/catal12020110

Academic Editor: Jorge Bedia

Received: 20 December 2021

Accepted: 14 January 2022

Published: 18 January 2022

Publisher's Note: MDPI stays neutral with regard to jurisdictional claims in published maps and institutional affiliations.

Copyright: (C) 2022 by the authors. Licensee MDPI, Basel, Switzerland. This article is an open access article distributed under the terms and conditions of the Creative Commons Attribution (CC BY) license (https:// creativecommons.org/licenses/by/ $4.0 /)$.

\begin{abstract}
Nowadays, materials with great potential for environmental protection are being sought. Metal-organic frameworks, in particular those with cobalt species as active sites, have drawn considerable interest due to their excellent properties. This review focuses on describing cobalt-based MOFs in the context of light-triggered processes, including dye degradation, water oxidation and splitting, carbon dioxide reduction, in addition to the oxidation of organic compounds. With the use of Co-based MOFs (e.g., ZIF-67, Co-MOF-74) as photocatalysts in these reactions, even over $90 \%$ degradation efficiencies of various dyes (e.g., methylene blue) can be achieved. Co-based MOFs also show high TOF/TON values in water splitting processes and $\mathrm{CO}_{2}$-to- $\mathrm{CO}$ conversion. Additionally, the majority of alcohols may be converted to aldehydes with efficiencies exceeding $90 \%$ and high selectivity. Since Co-based MOFs are effective photocatalysts, they can be applied in the elimination of toxic contaminants that endanger the environment.
\end{abstract}

Keywords: Co-MOFs; cobalt active sites; water oxidation; $\mathrm{CO}_{2}$ reduction; light-driven degradation of dyes; oxidation of alcohols

\section{Introduction}

When thinking of an inexhaustible source of energy, the sun comes first. Sunlight offers a huge package of energy, and the only limitation is the ability to harvest it properly. Therefore, the scientists of the world are in a race to develop a method of harvesting light that can revolutionize every aspect of our daily lives. Photocatalysts can utilize light energy and transfer it to form or break bonds in molecules. Technologies based on photocatalysis, such as the production of clean fuels, the reduction of greenhouse gases or the degradation of pollutants, hold great promise for energy and environmental protection [1-5]. Up to now, the most investigated light-driven processes are degradation of dyes [6], water splitting, and oxygen/hydrogen evolution reactions (OER/HER) [7-10], in addition to carbon dioxide reduction $[11,12]$. Certainly, these reactions can be carried out with noble metals or photocatalytically active metal oxides [13]. However, they are limited either by high price or poor selectivity in obtaining the desired product. Metal-organic frameworks (MOFs) are a new class of porous crystalline materials that have been shown to be very useful in photosensitive processes. MOFs are built of inorganic nodes (metal ions or metal clusters), connected to organic linkers [14]. They are famed for their well-developed surface area, rich topology, tuneable porous structure, and unique morphology of particles [15]. Due to their features, MOFs are applied in various areas, such as adsorption, gas separation, sensing, energy storage, drug delivery, and catalysis [16-18].

Conventional photocatalysts face issues with accessibility to the catalytic centres. MOFs, due to their high porosity, can provide ample access to the active sites that ensure product separation [19-21]. Briefly, a heterogeneous catalytic reaction consists of five main steps: (i) diffusion of the reactant to the catalyst surface, (ii) reactants adsorption on the surface, (iii) chemical reaction, (iv) products desorption, and (v) products diffusion. If there 
is a high affinity between catalyst and adsorbate, the activation energy of the reaction can be greatly reduced. The sorption properties of MOFs can be tuned via changing the pore size and inorganic nodes [22,23]. In a photocatalytic reaction, the driving force is light. A photocatalyst is a semiconductor material that has valence (VB) and conduction (CB) bands. The energy difference between these two bands is called the band gap, most often in the range of 1.8-3.5 eV. Light, as a causative force in photocatalysis, induces the generation of electron-hole pair $\left(\mathrm{e}^{-}-\mathrm{h}^{+}\right)$. The energy of the photons must overcome the band gap of the semiconductor to excite an electron from VB to CB. However, only a small amount of electrons can be transferred to the surface to drive a chemical reaction. This is due to the recombination of electrons and holes, which can generate either heat or light [24].

The linkers in MOFs and light-sensitive guests confined within the framework can improve the scope of light absorption [25-27]. The predominance of aromatic compounds as linkers allows the absorption of irradiation in a wide range, from UV to visible light. As a result, excitation and transfer of electrons i.e., $n-\pi^{*}$ or $\pi-\pi^{*}$, occurs. To efficiently separate the charges upon exposure to light, MOFs usually require chromophores (photosensitizers). They sensitize the system to the action of light and promote an electron to jump to higher energy levels. The electron transferred to the MOF induces a charge difference and forms electron-hole pairs that drive chemical reactions [28]. To protect the system from degradation, a sacrificial agent is required to supply electrons. Homogeneously distributed and stabilized metal nodes in MOFs act as catalytic active sites. As semiconductors, they reduce the recombination of photogenerated charge carriers [29]. Moreover, post-synthetic modifications (PSMs) of MOFs e.g., defect-engineering or doping with narrow band gap co-catalysts, can further improve the performance of MOFs [21,30,31].

Amongst the wide variety of MOFs, cobalt-based MOFs are broadly used in conventional heterogeneous catalysis e.g., ZIF-67 (ZIF = Zeolitic Imidazolate Framework) [32,33], Co-btc $\left(\mathrm{H}_{3}\right.$ btc $=1,3,5$-benzenetricarboxylic acid $)[34,35],\left\{\left[\mathrm{Co}(1,3-\mathrm{bdc})(4-\mathrm{tbt})_{2 / 3}\right] \times\left(\mathrm{H}_{2} \mathrm{O}\right)(\mathrm{DMF})_{1.5}\right\}_{\mathrm{n}}$ (4-tbt = 1,3,5-tris(4-pyridyl)benzene; $\mathrm{H}_{2}$ bdc = isophtalic acid) [36], Co-tpt (tpt = 2,4,6-tris(4pyridyl)-1,3,5-triazine) [37], Co-MOF-74 [38], and more [39]. They exhibit catalytic activity after pyrolysis, even after decomposition of frameworks [40,41]. For example, MOF-derived cobalt nanoparticles are used to catalyse amines synthesis [42], or MOF-derived carbon composites are applied in oxidation processes [43]. Co species acting as catalytic active sites can also be introduced into non-cobalt MOFs e.g., in the case of Co21-MOF-5 applied in $\mathrm{CO}_{2}$ conversion to carbonates [44]. Cobalt active sites have been investigated mainly in $\mathrm{Co}_{3} \mathrm{O}_{4}$ and cobalt complexes. In metal oxide, cobalt creates tetrahedral $\mathrm{Co}^{2+}$ and octahedral $\mathrm{Co}^{3+}$ active sites. It is rather puzzling, which sites are more suitable for specific reactions. For $\mathrm{Co}_{3} \mathrm{O}_{4}$, it has been suggested that both $\mathrm{Co}^{2+}$ and $\mathrm{Co}^{3+}$ species are effective for the oxygen evolution reaction [45]. In Co-based complexes for hydrogen generation, an induction period has been recorded $[46,47]$. It is usually assigned to the multiple equilibriums that require a transition from $\mathrm{Co}^{2+} / \mathrm{Co}^{3+}$ to their reduced intermediates or hydrides. In other applications, such as $\mathrm{CO}_{2}$ reduction, $\mathrm{Co}(\mathrm{I})$ species have been observed to exhibit strong nucleophilic properties. Therefore, $\mathrm{Co}(\mathrm{I})$ demonstrate high reactivity with $\mathrm{CO}_{2}$, $\mathrm{H}_{3} \mathrm{O}^{+}$, and small organic molecules [48]. There are more conclusions about the catalytic activity of cobalt for $\mathrm{Co}_{3} \mathrm{O}_{4}$ and cobalt complexes than for Co species in MOFs. In the ZIF structure, cobalt coordinates to the nitrogen from imidazolate motifs and forms Co-N bonds. In turn, in carboxylic acid-based MOFs, $\mathrm{Co}_{x}\left(\mu_{\mathrm{x}}-\mathrm{OH}\right)$ bridges are present. Therefore, the comparison of the Co catalytic sites from metal oxide and MOFs is theoretical and can only be suggestive. In addition, differences in $\mathrm{Co}^{2+} / \mathrm{Co}^{3+}$ ratios may occur in cobalt-containing catalysts, and it is difficult to obtain reproducible and comparable materials. Nevertheless, the scaffold of MOFs stabilizes the Co-nodes, immobilizes the linkers, and confines the catalytically active guests. This ensures an easily accessible interface and high dispersion of $\mathrm{Co}$ active sites. Moreover, MOFs can be recovered after the catalytic reaction due to their solid structure.

Noble metals such as $\mathrm{Pt}$ and $\mathrm{Rh}$, metal oxides e.g., $\mathrm{TiO}_{2}$ are great promoters in light-triggered catalysis, but they are expensive and can catalyse the reaction backwards, 
hence the search for new materials and the use of other metals must be considered [49]. Up to now, various MOFs have been successfully utilized as catalysts in processes such as water splitting [50-53], $\mathrm{CO}_{2}$-to-CO conversion [54,55], photocatalytic degradation of dyes [56], and the oxidation of organic compounds [57]. Moreover, there are many methods to modify MOFs for photocatalysis i.e., ligand functionalization, mixed-metal/linker strategy, organic compounds sensitization, metal ion/ligand immobilization and doping [58]. Cobalt-based MOFs are well known in traditional heterogeneous catalysis and are increasingly recognized specifically in photocatalysis. However, the versatility of Co-MOFs in photocatalytic processes has not yet been sufficiently emphasized. For this reason, the following review focuses primarily on the application of cobalt-based MOFs and their composites in light-driven reactions, such as dye degradation, water oxidation for $\mathrm{O}_{2}$ evolution, water splitting for $\mathrm{H}_{2}$ generation, $\mathrm{CO}_{2}$ reduction to $\mathrm{CO}$, and oxidation of organic compounds (Figure 1). A compilation of approaches to the applicability of Co-MOFs, a comparison of their efficiencies, and suggestions on the mechanisms driving photocatalytic reactions have been provided. Additionally, interesting examples of Co-MOFs with high catalytic activity and/or selectivity for the desired product are presented. It should be mentioned that the performance of MOFs is often reported in different ways e.g., as turnover number (TON), turnover frequency (TOF), the amount of generated product, or even the quantum efficiency of the catalyst. This could pose an issue for the comparative analysis $[59,60]$. The advantages of Co-MOFs in relation to other traditional catalysts have also been highlighted taking into account their regenerability, stability, cost, and reusability.

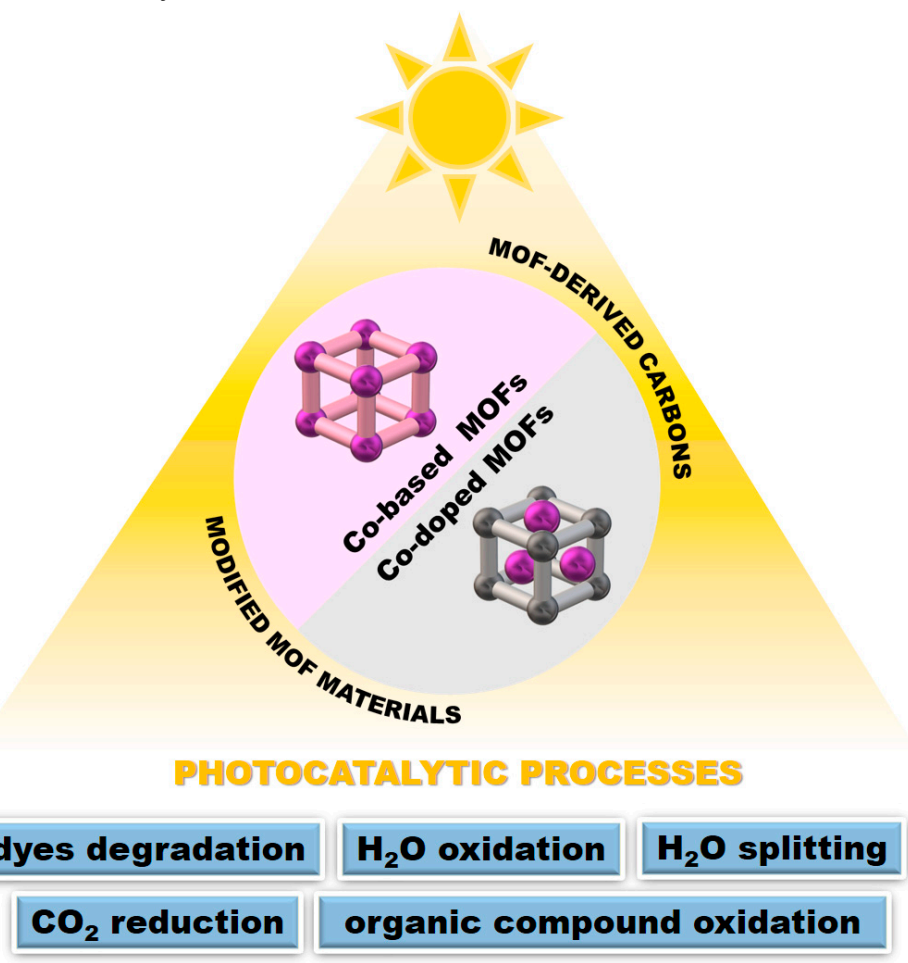

Figure 1. The applications of cobalt-based MOFs, MOFs doped with $\mathrm{Co}^{2+}$ species, and MOF-derived materials, in various photocatalytic processes i.e., degradation of dyes, water oxidation for $\mathrm{O}_{2}$ evolution, water splitting for $\mathrm{H}_{2}$ generation, $\mathrm{CO}_{2}$ reduction to $\mathrm{CO}$, and oxidation of organic compounds.

\section{Photocatalytic Degradation of Dyes}

Textile, paper, and clothing industries are the main cause of the existence of organic dyes in water, which contributes to significant environmental pollution. Industrial effluents that contain toxic and non-biodegradable colorants are highly dangerous toward living organisms, thus their removal from water reservoirs is necessary. Various processes e.g., membrane filtration [61], ion exchange [62], adsorption [63], ozonation [64], 
coagulation-flocculation [65], or photocatalytic degradation [66] are applied in order to eliminate dyes present in water. Over the past few years, photodegradation has become popular since it carries numerous advantages. The reaction may be conducted at room temperature and lasts only a few hours. Moreover, contaminants can be mineralized to harmless molecules (e.g., water, carbon dioxide) through the in situ generation of radicals without forming harmful secondary products. Light intensity, $\mathrm{pH}$, or adsorption properties can affect the photodegradation of dyes. With the increase in the irradiation intensity, reactive oxygen species are generated at a higher rate and the photocatalytic performance is improved. Electrostatic interactions between the reactants are determined by the $\mathrm{pH}$ value, however, each catalyst may work more efficiently at a different $\mathrm{pH}$. Although the moderate dye adsorption enhances the degradation yield, after exceeding a certain limit it can be unfavourable. Not only do fewer photons reach surface active sites, but also the molecules of a dye can act as sensitizers that absorb electrons, scattering them in unwanted directions.

In the first step of the photocatalytic process, pollutants are transported from the environment to the surface of the photocatalyst where oxidation-reduction reactions take place. Photogenerated electrons in the $\mathrm{CB}$ and holes in the VB force these reactions to occur. Afterward, the products are desorbed and returned to the liquid phase. In order to generate electron-hole pairs, the energy of the photons must be equal to or exceed the band gap of the photocatalyst [67]. In the photodegradation of dyes, materials such as oxides $\left(\mathrm{TiO}_{2}, \mathrm{ZnO}\right)$, metal salts, or chalcogenides (e.g., $\left.\mathrm{CdS}, \mathrm{Sb}_{2} \mathrm{~S}_{3}, \mathrm{MnS}\right)$, including their composites were described, although recently cobalt-based MOFs have been willingly utilized [68]. The large surface area, a wide selection of metallic centres and organic linkers, as well as the possibility to control morphological properties make MOFs excellent potential photocatalysts $[68,69]$.

ZIF-67, synthesized via hydrothermal reaction from cobalt salts, (e.g., $\left.\mathrm{Co}\left(\mathrm{NO}_{3}\right)_{2} \cdot 6 \mathrm{H}_{2} \mathrm{O}\right)$ and 2-methylimidazole as organic linker, has a large specific surface area and is highly porous, hence it exhibits numerous applications in photocatalysis. The mechanism of the photocatalytic degradation of dyes using ZIF-67 is simple (Figure 2). In order to regain the stable state, the electron is taken from the water molecule causing its oxygenation into $\bullet \mathrm{OH}$ active form. Additionally, the electron that is present in the LUMO and the oxygen from ZIF-67 surface form $\bullet \mathrm{O}_{2}{ }^{-}$that is subsequently converted into $\bullet \mathrm{OH}$. Dye molecules may be cleaved by these radicals to successfully conduct the photodegradation $[70,71]$.

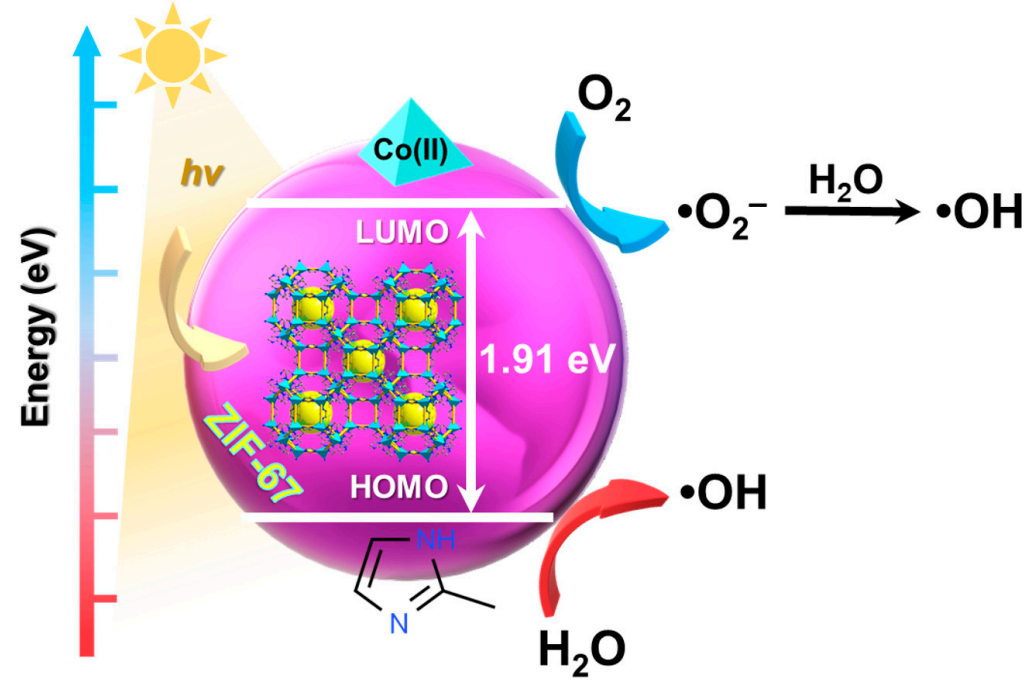

Figure 2. Scheme representing the photodegradation reaction mechanism involving ZIF-67.

This MOF has already been used in the photodegradation of methyl orange [70], methyl blue [71], and rhodamine B [71]. Over $88 \%$ of methyl orange was decomposed after one hour, which is related to reactive charge carriers' formation by the photoactive particles of ZIF-67. Furthermore, ZIF-67 exhibited high photostability and only a small 
decrease in its photocatalytic activity is noticeable after three degradation cycles [70]. ZIF-67 used in methyl blue and rhodamine B removal was subjected to argon annealing treatment to improve the photocatalytic activity. In one hour, $85.7 \%$ and $54.8 \%$ of dyes were degraded, respectively. Compared with the ZIF-67, ZIF-67(Ar) displayed better tolerance toward $\mathrm{pH}$ changes, therefore higher degradation rates in a wide $\mathrm{pH}$ range were observed [71]. New nanocomposite ZIF-67@CoWO $@$ @ CoS was synthesized from ZIF-67 in addition to $\mathrm{CoWO}_{4}$ and $\mathrm{CoS}$ nanoparticles, and applied as a photocatalyst for methylene blue degradation [72]. Given that $\mathrm{CoS}$ is biocompatible and cheap, and, moreover, in the presence of $\mathrm{Co}(\mathrm{II})$ ions peroxide substrates, may be decomposed into $\bullet \mathrm{OH}$, it can be used to activate ZIF@CoWO 4 . This allows the generation of free radicals under visible light irradiation. ZIF-67@CoWO $@$ @ CoS showed approximately 100\% efficiency in methylene blue photodegradation after only $10 \mathrm{~min}$ of irradiation. Both individual components' degradation effectiveness and the activity of ZIF-67@CoWO ${ }_{4}$ and ZIF-67@CoS are not as high as ZIF-67@CoWO ${ }_{4} @ \mathrm{CoS}$, which may result from the synergistic effects of pure MOF, $\mathrm{CoWO}_{4}$, and $\mathrm{CoS}$ as well as the narrow band gap energy in the ZIF-67@CoWO $@$ @oS The novel catalyst turned out to be very stable and even after eight reuses its activity loss is insignificant.

ZIF-67 and ZIF-8 were combined to create a single structure Co/Zn-ZIF that can be applied in the photodegradation of indigo carmine under solar-simulated irradiation [73]. One-pot synthesis was conducted at room temperature in order to incorporate cobalt into the ZIF-8 structure. A very important property of the new, bimetallic Co/Zn-ZIF is its excellent stability in aqueous solutions, which is a crucial factor for any material used in photodegradation processes. Less than three hours of irradiation in the presence of $\mathrm{Co} / \mathrm{Zn}$-ZIF is required to remove almost $100 \%$ of the dye. Due to the fact that hydroxyl ions facilitate the generation of hydroxyl radicals, which are behind the indigo carmine decomposition, the catalytic activity of a $\mathrm{MOF}$ is higher in an alkaline environment.

Two $\mathrm{H}_{2} \mathrm{~L}$ (5-(4-(imidazolyl-1-yl)phenyl) isophthalic acid)-based Co(II) MOFs-[Co(L)(tib) $\left.\left(\mathrm{H}_{2} \mathrm{O}\right)_{2}\right]_{\mathrm{n}}$ and $\left[\mathrm{Co}(\mathrm{L})(\mathrm{bip})_{0.5} \ln _{\mathrm{n}}\right.$ (tib = 1,3,5-tris(1-imidazolyl)benzene; bip = 3,5-bis(1-imidazolyl)pyridine ether) were obtained under solvothermal conditions and utilized in methylene blue as well as methyl violet removal [74]. With the use of the first material, within two hours of UV irradiation the degradation rates toward methylene blue and methyl violet were $75.2 \%$ and $92.1 \%$, while for the second Co-MOF were $57.7 \%$ and $89.7 \%$. Behind the great photocatalytic properties of $\left[\mathrm{Co}(\mathrm{L})(\mathrm{tib})\left(\mathrm{H}_{2} \mathrm{O}\right)_{2}\right]_{\mathrm{n}}$ and $\left[\mathrm{Co}(\mathrm{L})(\mathrm{bip})_{0.5}\right]_{n}$, are, respectively, a $2 \mathrm{D}$ stacking structure and a macroporous structure, since they allow more active sites to be exposed. As a consequence, multiple free radicals, which take part in the decomposition of dye molecules, are formed. In addition, both materials were examined for reusability in the elimination of methyl violet, for which a slight decline (from $92.1 \%$ to $91.5 \%$ for $\left[\mathrm{Co}(\mathrm{L})(\mathrm{tib})\left(\mathrm{H}_{2} \mathrm{O}\right)_{2}\right]_{\mathrm{n}}$ and from $89.7 \%$ to $88.9 \%$ for $\left[\mathrm{Co}(\mathrm{L})(\mathrm{bip})_{0.5}\right]_{\mathrm{n}}$ ) in photocatalytic performance was observed after three recycles.

Methylene blue, methyl violet, and rhodamine $\mathrm{B}$ can also be decomposed by the novel, solvothermally synthesized Co-based MOFs - $\left[\mathrm{Co}_{4}(\mathrm{bbibp})_{5}(\mathrm{HCOO})_{8}\left(\mathrm{H}_{2} \mathrm{O}\right)_{2}\right]_{n}$ and $\left[\mathrm{Co}\left(\text { bimmb) }\left(\mathrm{NO}_{3}\right)_{2}\right]_{\mathrm{n}}\right.$ (bbibp = 4,4-bis(imidazol-1-yl)biphenyl; bimmb = 1,4-bis(imidazol-1ylmethyl)benzene) [75]. After 75 min of UV irradiation, almost $100 \%$ of methylene blue, $49.2 \%$ of methyl violet, and $39 \%$ of rhodamine B were degraded using the first MOF. For the second material, the degradation rates of these dyes were as follows: $94 \%, 68.7 \%, 64.4 \%$. The highest photocatalytic activity toward methylene blue may arise from the differences in the sizes of dye molecules, as due to the smaller molecule, more interactions between active sites and targets could occur. As stability is an important factor when photocatalysts are considered for industrial applications, MOFs have been reused in methylene blue degradation. The differences in their activity are almost imperceptible, therefore they can be successfully used in the photocatalytic degradation of dyes.

Cobalt(II) salt and $\mathrm{H}_{3} \mathrm{~L}$ (5-fluorine-3-(3,5-dicarboxylphenoxy)benzoic acid) in the presence of bib (1,1'-(1,4-butanediyl)bis (imidazole)) linker were substrates in the preparation of tetranuclear $\left[\mathrm{Co}_{4}\left(\mu_{3}-\mathrm{OH}\right)_{2}\left(\mathrm{H}_{2} \mathrm{O}\right)_{2}(\mathrm{~L})_{2}(\mathrm{bib})_{1.5}\left(\mathrm{CH}_{3} \mathrm{CN}\right) \times 3 \mathrm{H}_{2} \mathrm{O} \times \mathrm{CH}_{3} \mathrm{CN}\right]$ as well as 
$\left[\mathrm{Co}_{8}\left(\mu_{3}-\mathrm{OH}\right)_{4}(\mathrm{~L})_{4}(\mathrm{bib})_{4} \times 8 \mathrm{CH}_{3} \mathrm{CN}\right]$ MOFs. Both materials are characterized by unique 3D Co-based frameworks, which are the result of the syntheses carried out under different temperatures. These MOFs have been applied as photocatalysts for the removal of methyl violet, whose degradation rates after $100 \mathrm{~min}$ of UV irradiation were $67.99 \%$ and $78.22 \%$, respectively [76]. Despite identical conditions, differences caused by dissimilar photosensitivities, electron communication properties, or band gaps can be noticed. $\left[\mathrm{Co}_{8}\left(\mu_{3}-\mathrm{OH}\right)_{4}(\mathrm{~L})_{4}(\mathrm{bib})_{4}\right.$ $\left.\times 8 \mathrm{CH}_{3} \mathrm{CN}\right]$ emerged as a better photocatalyst. Furthermore, it can be recycled and used multiple times, since there is only a little decrease in its photocatalytic activity.

CUST-501- $\left[\mathrm{Co}_{2}\left(\mathrm{H}_{2} \mathrm{O}\right)(\mathrm{tfBDC})_{2}(\mathrm{Phen})_{2}\right](\mathrm{tfBDC}=$ tetrafluoroterephtalic acid; Phen $=1,10$-Phenanthroline monohydrate) is another MOF that has been used to eliminate dyes such as rhodamine B from water [77]. Its role as a catalyst is based on activating peroxymonosulfate $\left(\mathrm{HSO}_{5}{ }^{-}\right)$under $\mathrm{UV}$ irradiation, which triggers the generation of free radicals $\left(\mathrm{SO}_{4}{ }^{--}\right)$(Figure 3). A total of $100 \%$ of rhodamine $\mathrm{B}$ was degraded in about $15 \mathrm{~min}$, which indicates that CUST-501 has potential in water treatment. Additionally, the photocatalyst shows unchanged efficiency after two recycling cycles.

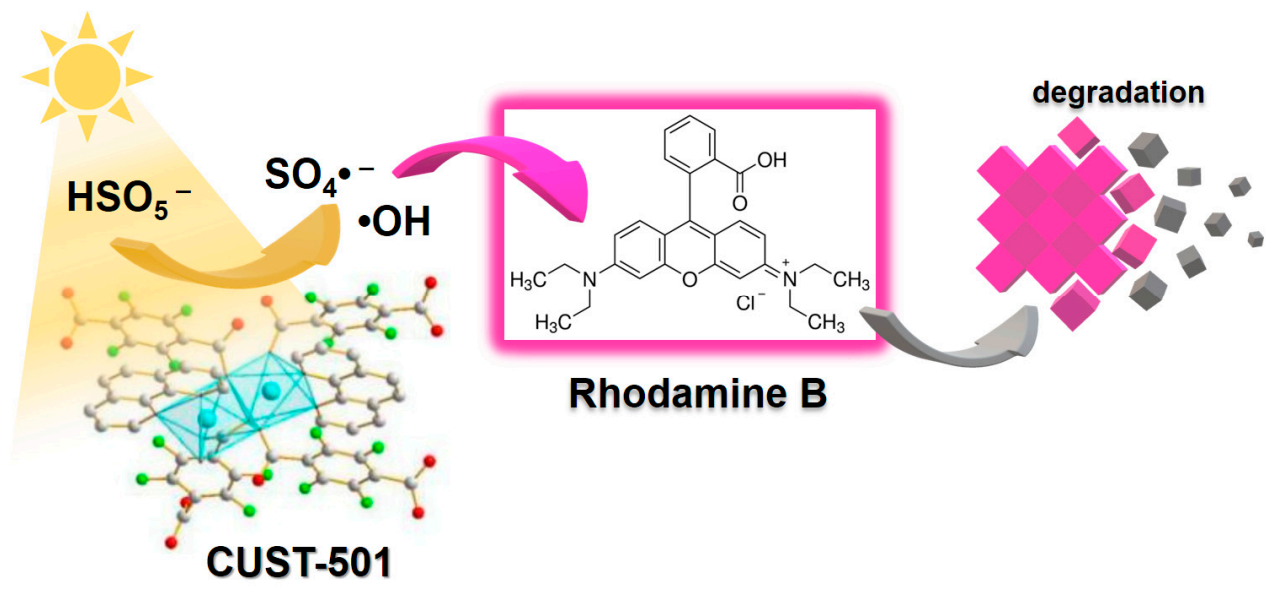

Figure 3. Schematic view of rhodamine B photodegradation mechanism with the use of CUST-501.

The effective photodegradation of methylene blue and methyl violet under UV irradiation has been achieved with the use of hydrothermally obtained $\left\{\left[\mathrm{Co}(\mathrm{tib})_{2}(\mathrm{bimb})_{2}\right]\right.$ $\left.\times 4 \mathrm{H}_{2} \mathrm{O}\right\}_{\mathrm{n}}$ and $\left\{\left[\mathrm{Co}_{2}(\text { bipa })_{4}(\mathrm{bibp})_{6}\right]\right\}_{\mathrm{n}}$ (tib = 3-((4-(1H-1,2,4-triazol-1-yl)benzyl)oxybenzoic acid; bimb = 1,4-bis(imidazole-1-ylmethy)benzene; bipa = 2-(4-carboxy-2-nitrophenoxy)-6nitroterephtalic acid; bibp = 4,4'-bis(imidazolyl)biphenyl) [78]. The first MOF contributed to the decomposition of $92.1 \%$ and $89.3 \%$ of methylene blue and methyl violet in two hours, whereas for $\left\{\left[\mathrm{Co}_{2}(\mathrm{bipa})_{4}(\mathrm{bibp})_{6}\right]\right\}_{\mathrm{n}}$ the results were as follows: $92.8 \%, 93.7 \%$. The high degradation rates arise from the specific structure of the materials. Concurrently, these MOFs possessed a 3D layered stacked structure, as the $2 \mathrm{D} \rightarrow 3 \mathrm{D}$ structure enabled forming a $2 \mathrm{D}$ sheet structure when the photocatalytic process occurs. Thus, exposing the active sites is simpler than with the standard interpenetrating 3D structure.

DABCO (1,4-diazabicyclo [2.2.2] octane) was used as a linker in the synthesis of yet another Co-MOF, which was subsequently encapsulated with methyl orange (MO) and methylene blue (MB) to obtain two composites-MO@Co-MOF and MB@Co-MOF. The effectiveness of all materials in the degradation of Eriochrome Black $\mathrm{T}$ under visible light was compared [79]. For Co-MOF, MO@Co-MOF, and MB@Co-MOF the photocatalytic efficiencies after four hours reached $78.9 \%, 92.0 \%$, and $99.7 \%$. The dyes loaded onto CoMOF serve as an antenna that strongly captures the light. Moreover, they not only act as photosensitizers but also as electron donors for the Co-MOF photocatalyst. This results in the separation of charge carriers at the interface between sensitizer and photocatalyst. MB@Co-MOF was subjected to five recycles in order to check its reusability and photostability. A slight decrease (to $95.2 \%$ ) in photoactivity was observed, which is caused by the small composite loss. 
Hydrothermal synthesis was conducted to obtain 3D Co(II) MOF- $\left[\mathrm{Co}(\mathrm{L})_{0.5}(\mathrm{OBA})\right]_{\mathrm{n}}$, based on $\mathrm{H}_{2} \mathrm{OBA}\left(4,4^{\prime}\right.$-oxybis(benzoate)) and L (1,6-bis(5,6-dimethylbenzimidazolyl)hexane) ligands. This material has been utilized in methylene blue degradation, $93.8 \%$ of which was eliminated from water solution after $135 \mathrm{~min}$ of visible light irradiation [80]. The reaction mechanism involved inducing $\mathrm{OBA}^{2-}$ and $\mathrm{L}$ ligands to generate $\mathrm{N}-\mathrm{Co}$ and/or O-Co charge transfer. As a result, photoinduced electrons from HOMO were transferred to LUMO. Returning to a stable state requires the delivery of an electron, which was obtained from $\mathrm{H}_{2} \mathrm{O}$. In the meantime, the electron present in LUMO reduced $\mathrm{O}_{2}$ in water to $\bullet \mathrm{O}_{2}{ }^{-}$, which afterward reacted with $\mathrm{H}^{+}$. Hydroxyl radical formed from both $\mathrm{H}_{2} \mathrm{O}$ and $\bullet \mathrm{O}_{2}{ }^{-}$is responsible for methylene blue photodegradation.

Anchoring trimetallic $\mathrm{Cu}-\mathrm{Co}-\mathrm{Ni}$ nanoparticles via direct impregnation onto aminomodified MOF-MIL-101(Fe) was applied to synthesize catalyst $\mathrm{NH}_{2}-\mathrm{MIL}-101(\mathrm{Fe}) @ \mathrm{CuCoNi}$, eliminating dyes such as methyl blue and crystal violet from wastewater [81]. The twohour continuous visible irradiation enabled the achievement of $99 \%$ and $93 \%$ dye removal rates, respectively. The composite retained the $83.1 \%$ degradation efficiency toward methyl blue and over $90 \%$ toward crystal violet, even after being reused five times. $\mathrm{NH}_{2}$-MIL101(Fe)@CuCoNi displayed a higher rate of light utilization in addition to catalytic activity, compared to MIL-101(Fe) and $\mathrm{NH}_{2}-\mathrm{MIL}-101(\mathrm{Fe})$. The proposed mechanism of methyl blue degradation is based on its transition to the excited state $\left(\mathrm{MB}^{*}\right)$ in an acidic environment (Figure $4 \mathrm{~A}$ ). Electrons were transferred by $\mathrm{MB}^{*}$ to the $\mathrm{Cu}-\mathrm{Co}-\mathrm{Ni}$ nanoparticles' ${ }^{\prime} \mathrm{NH}_{2-}$ MIL-101(Fe) conduction bands. Due to the formed heterojunction, electrons from the conduction bands of $\mathrm{Cu}-\mathrm{Co}-\mathrm{Ni}$ nanoparticles and photogenerated electrons were moved to $\mathrm{NH}_{2}-\mathrm{MIL}-101(\mathrm{Fe})$ reducing $\mathrm{Fe}^{3+}$ ions to $\mathrm{Fe}^{2+}$. Moreover, the leaching of $\mathrm{Cu}^{2+}$ ions also resulted in their reduction to $\mathrm{Cu}^{+}$. This synergistic effect favours the generation of $\bullet \mathrm{OH}$. In the valence bands of $\mathrm{Cu}-\mathrm{Co}-\mathrm{Ni}$ nanoparticles, the reaction of the water molecule with the holes $\left(h^{+}\right)$, formed by the constant electron irradiation, was carried out to produce - $\mathrm{OH}$. The degradation mechanism of crystal violet in a weakly alkaline environment was similar (Figure $4 \mathrm{~B}$ ). Oxygen adsorbed on the $\mathrm{NH}_{2}-\mathrm{MIL}-101(\mathrm{Fe})$ was converted by $\mathrm{Fe}^{2+}$ and $\mathrm{Cu}^{+}$ions into $\bullet \mathrm{O}_{2}{ }^{-}$. Additionally, holes that possessed oxidizing abilities mineralized dye molecules straightaway.
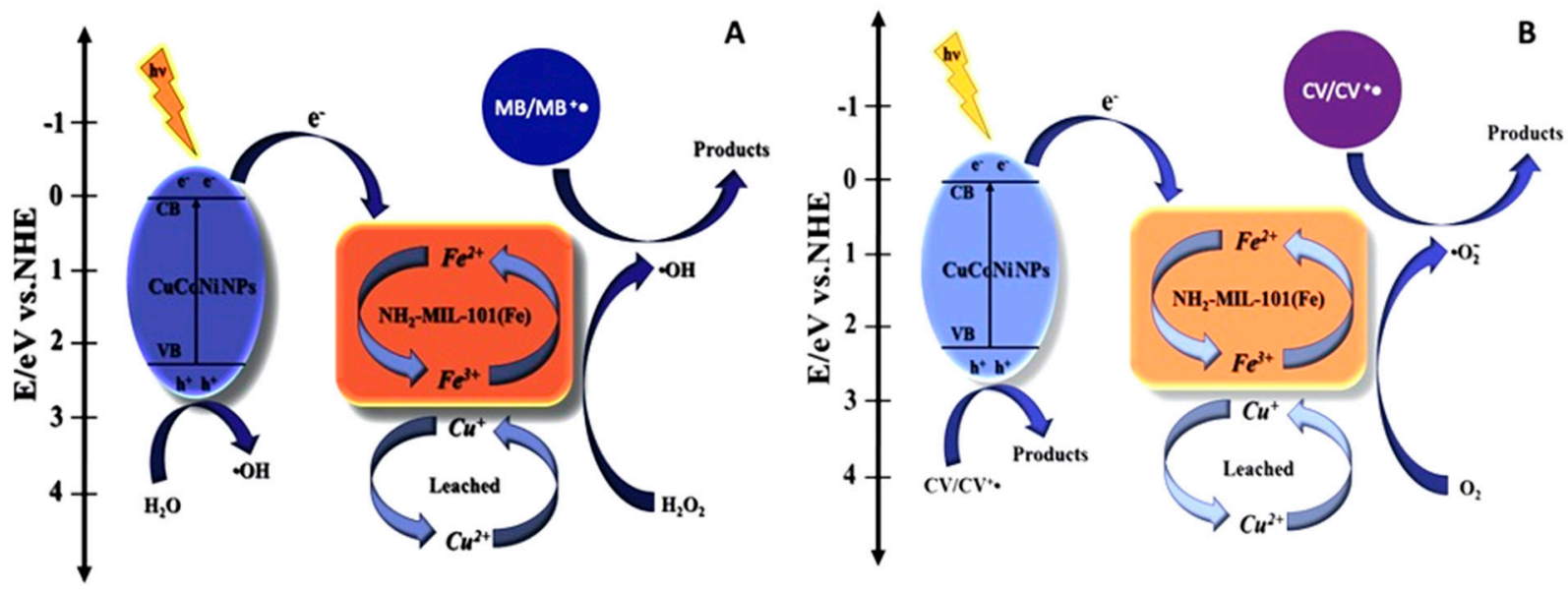

Figure 4. Scheme showing the photodegradation mechanism of: (A) methyl blue; (B) crystal violet by $\mathrm{NH}_{2}-\mathrm{MIL}-101(\mathrm{Fe}) @ \mathrm{CuCoNi}$ (Reprinted with permission [81]. Copyright 2020 Elsevier).

In this subsection, photocatalytic degradation as an effective strategy to remove dyes from the water is presented. Cobalt-based MOFs were willingly applied as catalysts in this process due to their efficiency, in addition to their high reuse potential. Organic pollutants such as methyl orange, methyl blue, methylene blue, methyl violet, or rhodamine B are most often subjected to photodegradation under light irradiation. With the use of CoMOFs, the degradation yields frequently exceed $90 \%$, even during a short reaction time, 
hence these materials show great potential in the elimination of various contaminants from water solutions (Table 1).

Table 1. Examples of Co-based MOFs used in the photocatalytic degradation of various dyes.

\begin{tabular}{|c|c|c|c|c|}
\hline Photocatalyst & Dye & $\begin{array}{l}\text { Photodegradation } \\
\text { Efficiency (\%) }\end{array}$ & Time & Ref. \\
\hline ZIF-67 & Methyl orange & $\sim 88$ & $1 \mathrm{~h}$ & [70] \\
\hline \multirow{2}{*}{ ZIF-67(Ar) } & Methyl blue & 85.7 & $1 \mathrm{~h}$ & \multirow{2}{*}[71]{} \\
\hline & Rhodamine B & 54.8 & $1 \mathrm{~h}$ & \\
\hline ZIF-67@CoWO $@$ @CoS & Methylene blue & $\sim 100$ & $10 \mathrm{~min}$ & [72] \\
\hline $\mathrm{Co} / \mathrm{Zn}-\mathrm{ZIF}$ & Indigo carmine & $\sim 100$ & $\sim 3 \mathrm{~h}$ & [73] \\
\hline \multirow{2}{*}[\mathrm{Co}(\mathrm{L})(\mathrm{tib})(\mathrm{H}_{2}\mathrm{O})_{2}]{$_{\mathrm{n}}$} & Methylene blue & 75.2 & $2 \mathrm{~h}$ & \multirow{2}{*}{ [74] } \\
\hline & Methyl violet & 92.1 & $2 \mathrm{~h}$ & \\
\hline \multirow{2}{*}[\mathrm{Co}(\mathrm{L})(\mathrm{bip})_{0.5}]{$_{\mathrm{n}}$} & Methylene blue & 57.7 & $2 \mathrm{~h}$ & \multirow{2}{*}{ [74] } \\
\hline & Methyl violet & 89.7 & $2 \mathrm{~h}$ & \\
\hline \multirow{3}{*}[\mathrm{Co}_{4}(\mathrm{bbibp})_{5}(\mathrm{HCOO})_{8}(\mathrm{H}_{2}\mathrm{O})_{2}]{$_{\mathrm{n}}$} & Methylene blue & $\sim 100$ & $75 \mathrm{~min}$ & \multirow{3}{*}[75]{} \\
\hline & Methyl violet & 49.2 & $75 \mathrm{~min}$ & \\
\hline & Rhodamine B & 39 & $75 \mathrm{~min}$ & \\
\hline \multirow{3}{*}[\mathrm{Co}(\text{bimmb})(\mathrm{NO}_{3})_{2}]{$_{\mathrm{n}}$} & Methylene blue & 94 & $75 \mathrm{~min}$ & \multirow{3}{*}[75]{} \\
\hline & Methyl violet & 68.7 & $75 \mathrm{~min}$ & \\
\hline & Rhodamine B & 64.4 & $75 \mathrm{~min}$ & \\
\hline $\begin{array}{c}{\left[\mathrm{Co}_{4}\left(\mu_{3}-\mathrm{OH}\right)_{2}\left(\mathrm{H}_{2} \mathrm{O}\right)_{2}(\mathrm{~L})_{2}(\mathrm{bib})_{1.5}\left(\mathrm{CH}_{3} \mathrm{CN}\right) \times\right.} \\
\left.3 \mathrm{H}_{2} \mathrm{O} \times \mathrm{CH}_{3} \mathrm{CN}\right]\end{array}$ & Methyl violet & 67.99 & $100 \mathrm{~min}$ & [76] \\
\hline$\left[\mathrm{Co}_{8}\left(\mu_{3}-\mathrm{OH}\right)_{4}(\mathrm{~L})_{4}(\mathrm{bib})_{4} \times 8 \mathrm{CH}_{3} \mathrm{CN}\right]$ & Methyl violet & 78.22 & $100 \mathrm{~min}$ & [76] \\
\hline CUST-501 & Rhodamine B & 100 & $15 \min$ & [77] \\
\hline $\multirow{2}{*}{\left[\mathrm{Co}(\mathrm{tib})_{2}(\mathrm{bimb})_{2}\right] \times 4 \mathrm{H}_{2} \mathrm{O}}_{\mathrm{n}}$ & Methylene blue & 92.1 & $2 \mathrm{~h}$ & \multirow{2}{*}{ [78] } \\
\hline & Methyl violet & 89.3 & $2 \mathrm{~h}$ & \\
\hline $\multirow{2}{*}{\left[\mathrm{Co}_{2}(\mathrm{bipa})_{4}(\mathrm{bibp})_{6}\right]}_{\mathrm{n}}$ & Methylene blue & 92.8 & $2 \mathrm{~h}$ & \multirow{2}{*}{ [78] } \\
\hline & Methyl violet & 93.7 & $2 \mathrm{~h}$ & \\
\hline MO@Co-MOF & Eriochrome Black T & 92 & $4 \mathrm{~h}$ & [79] \\
\hline MB@Co-MOF & Eriochrome Black T & 99.7 & $4 \mathrm{~h}$ & [79] \\
\hline$\left[\mathrm{Co}(\mathrm{L})_{0.5}(\mathrm{OBA})\right]_{\mathrm{n}}$ & Methylene blue & 93.8 & $135 \mathrm{~min}$ & [80] \\
\hline \multirow{2}{*}{$\mathrm{NH}_{2}$-MIL-101(Fe)@CuCoNi } & Methyl blue & 99 & $2 \mathrm{~h}$ & \multirow{2}{*}{ [81] } \\
\hline & Crystal violet & 93 & $2 \mathrm{~h}$ & \\
\hline
\end{tabular}

\section{Photocatalytic Reactions with Water}

\subsection{Photocatalytic Water Oxidation}

The oxidation of water, also known as the oxygen evolution reaction (OER), is a high energy barrier process that requires the transfer of four electrons. It can be triggered electrochemically or by the use of light. In the photo-driven water oxidation (PWO), the appropriate photosensitizer, catalyst, and sacrificial electron-hole donor are necessary. The purpose of PWO is to artificially mimic photosynthesis, the reactions of which occur on the surface of photocatalytically active materials [82]. The photocatalyst acts as a semiconductor that absorbs light and transfers solar energy to break chemical bonds in $\mathrm{H}_{2} \mathrm{O}$. This leads to the generation of the active oxygen species $(\mathrm{O} \bullet)$, hydroperoxy species $(\mathrm{OOH})$, and/or metal species $(\mathrm{M}-\mathrm{O} \bullet)$ at the active metal sites of the catalyst. During this process, oxidation of water with subsequent conversion to $\mathrm{O}_{2}$ takes place, which in acidic media can proceed as follows: $2 \mathrm{H}_{2} \mathrm{O} \rightarrow \mathrm{O}_{2}+4 \mathrm{e}^{-}+4 \mathrm{H}^{+}$and in the basic conditions: $4 \mathrm{OH}^{-} \rightarrow \mathrm{O}_{2}+4 \mathrm{e}^{-}+2 \mathrm{H}_{2} \mathrm{O}$. The oxidation process is also determined by light absorption, charge separation, and catalytic reaction on the surface. The most 
popular heterogeneous photocatalysts applied in $\mathrm{PWO}$ are $\mathrm{TiO}_{2}, \mathrm{BiVO}_{4}, \mathrm{WO}_{3}$, and $\alpha-$ $\mathrm{Fe}_{2} \mathrm{O}_{3}$. However, they encounter challenges related to the impaired four-electron migration kinetics, low light absorption, self-oxidation poisoning by photogenerated holes, and easy recombination of photogenerated charge carriers [83-87]. Hence, there is a great need for novel, highly active, reusable, and stable photocatalysts [10]. In the design of materials catalysing oxygen generation, it is important to develop strategies that can suppress recombination of electron-hole pair and photocorrosion of catalysts. The synthesis of composites characterized by high stability and the optimization of the catalytic reaction conditions allows photocatalysts to be protected against radiation damage $[88,89]$. When combining diverse materials, the different positions of the conduction and valence bands should be considered. Proper tailoring of the composite can affect the separation efficiency and the recombination rate of electron/hole pairs. In this case, cobalt acts mainly as a co-catalyst aiming to activate the other material with a wide band gap via accumulation of $\mathrm{e}^{-}$and $\mathrm{h}^{+}[90,91]$. In addition, cobalt as a dopant in MOFs tends to lower the overpotentials of the water oxidation process [92]. However, during the enrichment of the materials with cobalt species, the prevention of its leaching or inhomogeneous distribution should be taken into account.

MOFs are becoming increasingly popular in photocatalytic water oxidation due to the presence of linkers, capable of absorbing radiation as well as metal nodes that can act as catalytically active sites [51,93-95]. Cobalt-based coordination complexes with organic ligands have been intensively studied in photocatalytic water oxidation in the last decade [96]. For instance, $\left[\mathrm{Co}^{\mathrm{II}}\left(\mathrm{Me}_{6} \text { tren }\right)\left(\mathrm{OH}_{2}\right)\right]^{2+}\left(\mathrm{Me}_{6}\right.$ tren $=\operatorname{tris}\left(N_{,} N^{\prime}\right.$-dimethylaminoethyl $)$ amine $)$, $\left[\mathrm{Co}^{\mathrm{II}}(12-\mathrm{TMC})\right]^{2+} \quad(12-\mathrm{TMC}=1,4,7,10$-tetramethyl-1,4,7,10-tetraazacyclododecane), and $\left[\mathrm{Co}^{\mathrm{III}}(\mathrm{Cp} *)(\mathrm{bpy})\left(\mathrm{OH}_{2}\right)\right]^{2}\left(\mathrm{Cp}^{*}=\eta^{5}\right.$ pentamethylcyclopentadienyl) were tested to evolve $\mathrm{O}_{2}$. However, such complexes were more likely to produce $\mathrm{CO}_{2}$ rather than $\mathrm{O}_{2}$. This was caused by the oxidation of organic ligands and complex decomposition. Hence, cobalt complexes acted more as pre-catalysts, converting into catalytically active $\mathrm{Co}(\mathrm{OH})_{\mathrm{x}}$ nanoparticles [97]. Although there are reports suggesting ligand modification to stabilize Co-based complexes [98], MOFs have begun to displace them due to their unique properties. The far-reaching symmetry and iterative structure of MOFs, as well as their large specific surface area and increasing stability, have led to greater interest in their photocatalytic application [99].

A good example of a highly stable MOF, which revealed excellent photocatalytic water oxidation performance, is MAF-48 (MAF = metal-azolate framework), also known as $\mathrm{Co}_{4}$-bdt $\left[\mathrm{Co}_{8}(\mathrm{OH})_{4}\left(\mathrm{H}_{2} \mathrm{O}\right)_{2}(\mathrm{bdt})_{6}\right](\mathrm{bdt}=1,4$-benzenedi $(1 \mathrm{H}-1,2,3$-triazole $))$. The reaction was proceeded under visible light $(450 \mathrm{~nm})$ in the presence of photosensitizer $\left[\mathrm{Ru}(\mathrm{bpy})_{3}\right] \mathrm{SO}_{4}$ (bpy $=2,2^{\prime}$-bipyridine) and sacrificial electron acceptor $\mathrm{Na}_{5} \mathrm{~S}_{4} \mathrm{O}_{8}$. It was found that MAF-48 exhibits better performance in water oxidation than other known heterogeneous catalysts. Its TOF and TON were recorded to be $3.05 \mathrm{~s}^{-1}$ and $1.2 \times 10^{6}$, respectively [100]. TOF value is higher in comparison to those noted for $\mathrm{Co}_{3}$-in (Hin = isonicotinic acid), $\mathrm{Co}_{2}$-bbta (bbta $=1 \mathrm{H}, 5 \mathrm{H}$-benzo-(1,2-d:4,5-d' $)$ bistriazole $)$, Ni-bdt, Co-dobdc $\left(\mathrm{H}_{4}\right.$ dobdc $=2,5$-dihydroxyl1,4-benzenedicarboxylic acid), and Co-mim (Hmim $=2$-methylimidazole). In the case of cobalt ions, by increasing the coordination number of the hydroxide ligand, the catalytic performance improves. Isotope tracing experiments helped to explain the role of $\mu_{4}-\mathrm{OH}^{-}$ in MAF-48 during the process of water oxidation. It was shown that the bridging $\mathrm{OH}^{-}$ participate in the reaction, creating an oxygen vacancy that acts as a catalytic active centre, capping four coplanar cobalt ions (Figure 5). However, not all oxygen atoms from the $\mathrm{CO}_{4}$ cluster are simultaneously involved in the reaction. Moreover, oxygen coordinated on the $\mathrm{Co}_{4}$ is replaced by water molecules before $\mathrm{O}_{2}$ generation. Interestingly, the MAF-48 remains unchanged during and after the photo-driven reaction of water oxidation [100]. 


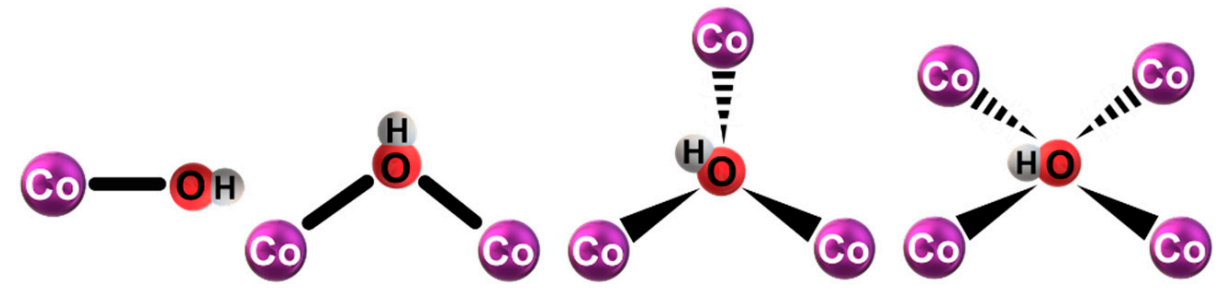

Figure 5. Models of the hydroxyl ions coordinated to the cobalt ions in the process of water oxidation.

A popular approach to enhance the efficiency of photocatalytic reactions is to enrich MOFs with cobalt [101]. For instance, a non-cobalt MOF, MIL-101(Cr) (MIL = Materials Institute Lavoisier) was impregnated with $\mathrm{Co}\left(\mathrm{NO}_{3}\right)_{2}$ as a precursor for cobalt oxide. The resulting photocatalytically active composite was coupled with $\left[\mathrm{Ru}(\mathrm{bpy})_{3}\right]^{2+}$ in order to be sensitized. A MOF with immobilized cobalt oxide nanoparticles exhibited high stability in PWO, and neither leaching nor aggregation of the particles was observed during the process. The catalyst indicated a TOF of $0.012 \mathrm{~s}^{-1}$ per cobalt atom in photocatalytic water oxidation, which is nine times higher than the TOF of corresponding $\mathrm{Co}_{3} \mathrm{O}_{4}$ without MOF support. However, the activity of the composite contributed to different cobalt species in the framework i.e., $\mathrm{Co}_{3} \mathrm{O}_{4}, \mathrm{Co}\left(\mathrm{NO}_{3}\right)_{2}$, and $\mathrm{Co}(\mathrm{OH})_{2}$ (molar ratio 77:17:6), which were established via XPS analysis. As a result, the prepared composites often varied in cobalt amounts, ranging from 1.4 to $4.9 \%$ wt. [102].

A POM@MOF composite was one of the first systems for oxygen evolution with the stable incorporation of two main components of photocatalysis (photosensitizer and catalyst) within the MOF. Paille and co-workers [103] prepared MOF-545 with sandwichtype polyoxometalate $\left(\mathrm{P}_{2} \mathrm{~W}_{18} \mathrm{Co}_{4}\right)$ for visible light-driven water oxidation at $\mathrm{pH} 8$, in the presence of a Ru-based molecular photosensitizer. MOF-545 is made of $\mathrm{Zr}$-oxide clusters and porphyrin moieties linkers known for their light-harvesting abilities, thereby reaction proceeded rapidly after light exposure $\left(\mathrm{TOF}=0.04 \mathrm{~s}^{-1}\right)$. The DFT calculations suggested that the active $\mathrm{Co}-\mathrm{OH}_{2}$ sites are accessible at the MOF-POM interface, and they are located in a hydrophilic catalytic pocket, ideal for the transfer of protons and $\mathrm{H}_{2} \mathrm{O}$ molecules. The same group synthesized POM@MOF composite in the form of thin films, which even further enhanced catalytic activity in water oxidation. The main goal was to achieve a high activity in oxygen evolution without the presence of noble metals, along with maintaining robustness and recyclability. The MOF acted again as a light-sensitive host for cobalt catalysts entrapped within the framework. The cobalt-based POM $\left(\mathrm{P}_{2} \mathrm{~W}_{18} \mathrm{Co}_{4}\right)$ with MOF545 were deposited on the indium tin oxide using various techniques such as drop-casting (DC) and electrophoresis (EP). It was confirmed that thin films are more effective in the water oxidation than the composite illuminated in suspension, with the following activity (TON): DC (1600) > EP (403) > suspension (75). Additionally, the films do not need to be centrifuge for reuse, hence there is no potential loss of material [104].

Another interesting example of a catalyst for water oxidation is MIL-101(Fe) encapsulated with cobalt-based polyoxometalate materials (POMs) i.e., $\mathrm{Co}_{2}$ and $\mathrm{Co}_{4}$ $\left(\left[\mathrm{Co}^{\mathrm{II}} \mathrm{Co}^{\mathrm{III}} \mathrm{W}_{11} \mathrm{O}_{39}\left(\mathrm{H}_{2} \mathrm{O}\right)\right]^{-7},\left[\mathrm{Co}_{4}\left(\mathrm{PW}_{9} \mathrm{O}_{34}\right)_{2}\left(\mathrm{H}_{2} \mathrm{O}\right)_{2}\right]^{-10}\right)$. POM@MOF composites revealed a non-leaching effect, which happens often in the case of MOFs doped with a single metal, cobalt oxides, and hydroxides. Moreover, POM@MOF showed significant structural stability and remarkable reusability without loss of activity in photocatalytic water oxidation. In the light-driven process, the composite acted as a light-harvester in the presence of the photosensitizer. The enhanced photocatalytic activity of $\mathrm{Co}_{2}$ and $\mathrm{Co}_{4} \mathrm{can}$ be related to the precise embedding of the POMs in the MOF and stabilization by electrostatic interactions. Adequate encapsulation of the POMs in the MOF cavities is only possible through an in situ reaction. More precisely, the POMs $(25 ; 29 \AA)$ must be smaller than the cavities but larger than the MOF window size $(5.5 ; 8.6 \AA)$. The combination of the two materials enabled effective oxidation of water because of the efficient ability of the POMs to separate electrons and holes. In the case of POMs, electrons are promoted to the sacrificial electron 
acceptor $\left(\mathrm{Na}_{2} \mathrm{~S}_{2} \mathrm{O}_{8}\right)$ via a photosensitizer, but the performance of this promotion is enhanced due to better absorption of visible light caused by the presence of MOFs. Moreover, the light absorption is higher for the composite than for the MOF alone, indicating that the combination of these materials increases their effectiveness in OER [101].

MOFs can create core-shell structures, as in Co-MOF-74@ZIF-67 catalysts via ligand exchange. While both MOFs consist of cobalt in nodes, they differ in linkers: ZIF-67 has 2-methylimidazole and Co-MOF-74 contains 2,5-dihydroxyterephthalic acid. ZIF-67 constitutes the core of the material and through controlled ligand exchange, it was possible to build Co-MOF-74 on its surface, which formed the shell (Figure 6). During the coreshell formation, it was feasible to control the thickness of the outer MOF layer from 10 to $50 \mathrm{~nm}$. The composite showed high oxygen evolution potential during water oxidation at pH 9.0 under visible light $(420 \mathrm{~nm})$. Moreover, it was recycled up to five times without a significant decrease in its activity. The oxygen generation efficiency was found to be for ZIF-67-9.8 $\mu \mathrm{mol}$, and for Co-MOF-74-11.8 $\mu \mathrm{mol}$, respectively. Combining the materials and using the system with the thickest shell resulted in $15 \mu \mathrm{mol}$ of $\mathrm{O}_{2}$ evolution. Attempts to increase the thickness of the shell by decreasing the molar ratio of ZIF-67 to the modifier led to the disintegration of particles morphology and amorphous bulk crystals were formed. However, this procedure can be extended, and different tricarboxylic linkers could be used to build up the shells of other types. It indicates that the presented method has a chance for further development in the light-driven oxygen evolution [105].

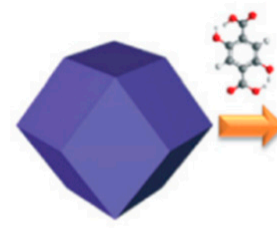

ZIF-67

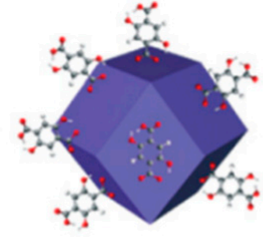

Competition coordination

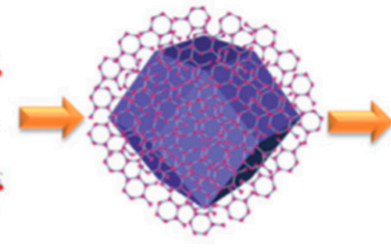

Formation of Co-MOF-74 shell

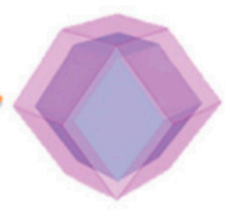

Core-shell Co-MOF-74@ZIF-67

Figure 6. The synthesis of Co-MOF-74@ZIF-67 composite for water oxidation (Reprinted with the permission [105]. Copyright 2018 The Royal Society of Chemistry).

Saliba et al. [106] prepared a nanometric (300 nm) ZIF-67 for oxygen evolution. They investigated the effect of $\mathrm{pH}$ and catalyst concentration on the catalytic activity of MOF in the oxidation of water. ZIF-67 acted as an electrocatalyst, accepting electrons from the photosensitizer $\left[\mathrm{Ru}(\mathrm{bpy})_{3}\right]^{2+}$. The system was tested in a wide $\mathrm{pH}$ range from 2.1 to 13.1 , in which the catalyst maintained a stable current density and thus remained active. The highest concentration of evolved $\mathrm{O}_{2}$ was $117.2 \mu \mathrm{mol}$, with a high reaction rate $\left(\mathrm{TOF}=0.035 \mathrm{~s}^{-1}\right.$ ) at a basic $\mathrm{pH}(9.0)$. It was observed that increasing the amount of MOF decreased its catalytic activity. It is worth noting that unmodified ZIF-67 is unstable in aqueous solutions [107], where hydrolysis of coordination bonds between nodes and linkers may occur. Therefore, the catalytic activity of ZIF-67 in aqueous solutions should also be ascribed to the released cobalt moieties. To stabilize ZIF-67, it can be modified [108], embedded on a suitable substrate [109], or doped with heteroatoms [110]. Ultrathin ZIF-67 nanosheets introduced on the $\alpha-\mathrm{Fe}_{2} \mathrm{O}_{3}$ hematite photoanodes can also be utilized as a catalyst for photoelectrochemical water oxidation (Figure 7). The cobalt cations present in ZIF-67 were ideal for the hole storage capability and effective charge transfer. It was the result of the high surface capacitance and very low surface charge transfer resistance. Additionally, MOF had a high amount of unsaturated $\mathrm{Co}-\mathrm{N}_{\mathrm{x}}$, which provided chemisorption of oxygen species such as $\mathrm{OH}$ and $\mathrm{OOH}$, and intense oxygen evolution [111]. 


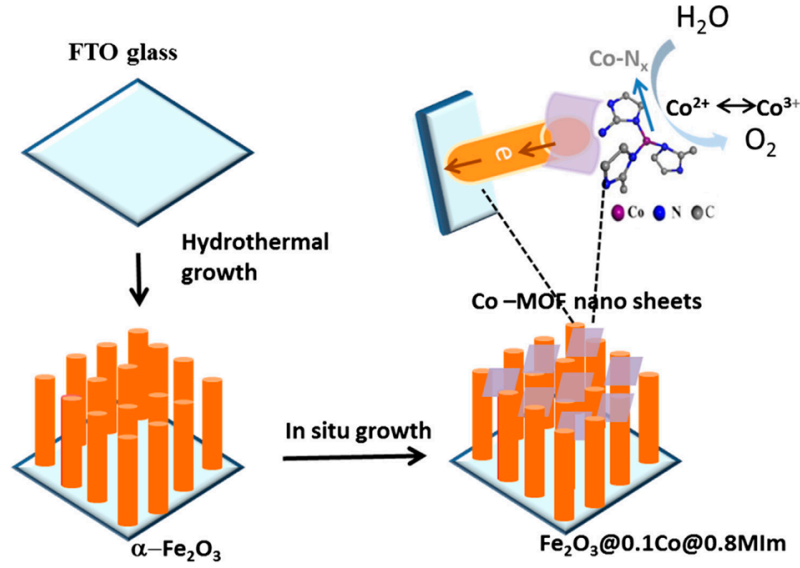

Figure 7. Scheme representing photoelectrocatalytic water oxidation on Co-MOF nanosheets as catalyst and $\alpha-\mathrm{Fe}_{2} \mathrm{O}_{3}$ hematite as photoanodes grown on FTO $\left(\mathrm{F}: \mathrm{SnO}_{2}\right)($ Reprinted with the permission [111]. Copyright 2018 Elsevier).

Dong et al. [112] reported a unique core-shell structure, synthesized using Co-Co Prussian blue (PB), an archetype of MOF characterized by a nanocubic structure. It consists of cyanide ligands $(-\mathrm{CN}-)$, coordinated octahedrally with transition metal ions. $\mathrm{Co}-\mathrm{Co} / \mathrm{PB}$ was applied as a precursor for CoP/NC-a cobalt(II) phosphide embedded in nitrogen and carbon matrices and prepared via phosphidation pyrolysis. The material obtained was distinguished by a core-shell $\mathrm{CoP} @ \mathrm{CoO}_{\mathrm{x}}$ structure, which ensured the electron transport under light irradiation $(460 \mathrm{~nm})$ for oxygen evolution. The amount of $4.5 \mathrm{mg}$ of the catalyst exhibited the best performance at $\mathrm{pH} 8$, yielding $901.5 \mathrm{mmol} \mathrm{g}^{-1} \mathrm{~h}^{-1}$ of the $\mathrm{O}_{2}$.

Similar to MOFs are metal-organic cages (MOCs), which are also composed of metal nodes and organic linkers but form supramolecular coordination complexes without long-range ordering. The highly catalytically active sites in MOC-1 i.e., Co-O and bis( $\mu$-oxo)dicobalt sites, showed potential for photoinduced water oxidation under visible light (470 nm LED lamp), in the presence of a photosensitizer [Ru(bpy) $\left.)_{3}\right] \mathrm{Cl}_{2}$ and $\mathrm{Na}_{2} \mathrm{~S}_{2} \mathrm{O}_{8}$ as the electron scavenger [113]. It was proved that the process is initiated through the transfer of electrons from excited $\mathrm{Ru}(\mathrm{bpy})]^{2+*}$ to $\mathrm{Na}_{2} \mathrm{~S}_{2} \mathrm{O}_{8}$. Subsequently, electrons originating from bis $\left(\mu\right.$-oxo)dicobalt and $\mathrm{Co}-\mathrm{O}$ sites of MOC- 1 are accepted by the oxidized $\left[\mathrm{Ru}(\mathrm{bpy})_{3}\right]^{3+}$, which facilitates water oxidation. The cobalt-based MOC-1 exhibited high stability and reusability, with only $1.85 \%$ of Co leaching out after the process. In comparison to other MOCs, such as MOC-2, MOC-3, MOC-4, the presence of both cobalt active sites in MOC-1 provided the best oxygen evolution rate $\left(80.4 \mathrm{mmol} \mathrm{g}^{-1} \mathrm{~h}^{-1}\right)$, showing their necessity for superior efficiency for superior efficiency [114].

\subsection{Photocatalytic Water Splitting}

Water splitting is a process of evolving hydrogen and oxygen $\left(2 \mathrm{H}_{2} \mathrm{O} \rightarrow 2 \mathrm{H}_{2}+\mathrm{O}_{2}\right)$, the main purpose of which is to achieve scalable and cost-viable solar hydrogen production (Figure 8). In recent years, interest in this process has been growing has it does not generate greenhouse gases. One of the main approaches for water splitting and the generation of $\mathrm{H}_{2}$ is to use photocatalysts with appropriate thermodynamic potential, a narrow band gap to harvest light, and an indication of resistance to photocorrosion [115]. Therefore, to enhance the efficiency of photoelectrocatalytic (PEC) water splitting, co-catalysts on semiconductors are often used. They not only provide additional catalytically active sites, but also facilitate redox reactions by suppressing charge recombination and unwanted reverse reactions [116]. At the moment, the quantum efficiency of current photocatalysts is usually less than $10 \%$. There are reports of external quantum efficiencies up to ca. 96\% [117], but these are rarely reproduced. Effective photocatalytic water splitting requires complex semiconductor systems coupled with catalysts operating in a broad light spectrum. 


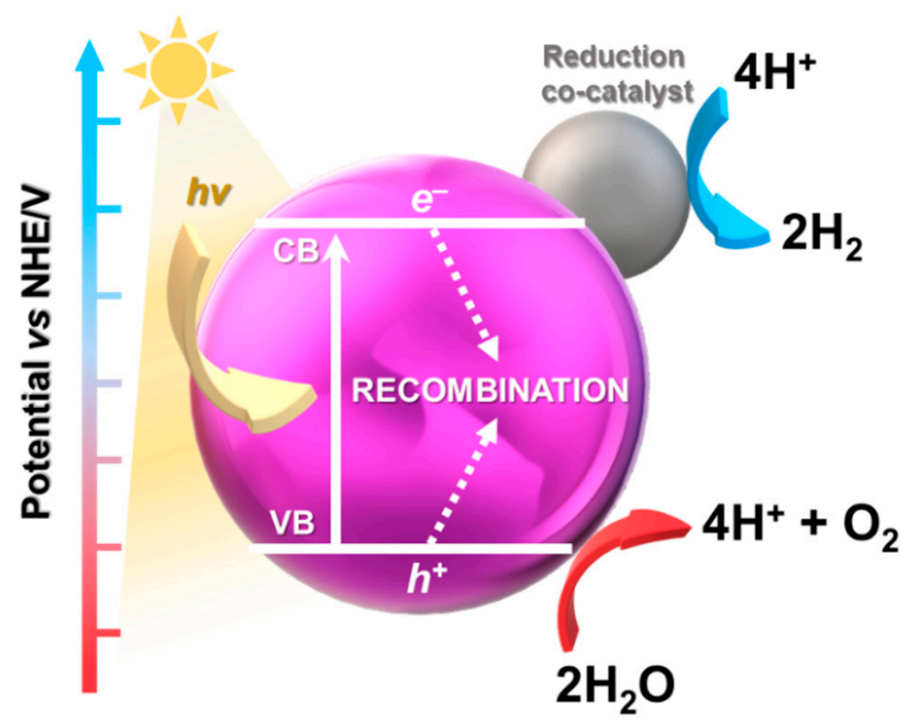

Figure 8. Scheme of light-triggered water splitting over a semiconductor photocatalyst.

In recent years, cobalt-based co-catalysts for water splitting i.e., $\mathrm{Co}(\mathrm{OH})_{2}, \mathrm{CoP}, \mathrm{Co}_{3} \mathrm{O}_{4}$, $\mathrm{Co}_{3} \mathrm{~N}, \mathrm{CoSe}_{2}$, and $\mathrm{Co}\left(\mathrm{S}_{\mathrm{x}}\right)$, have been appreciated for their high activity, low price, and robustness [90]. In the case of Co-MOFs, the stability and costs are mainly determined by the organic linkers. The linker synthesis is often complex, and they can decompose at high temperatures or diffuse out of the material in poorly chosen solvents [118]. When considering Co-MOFs as photocatalysts for redox reactions, in addition to stability, they should have a higher work function than n-type semiconductors. Due to the low Fermi level of the Co-based photocatalytic system, the induced electric field has to form a Schottky junction [90]. This is a potential barrier at the metal-semiconductor interface. MOFs can behave similar to microporous semiconductors that exhibit charge-separated states when exposed to light [119-121]. In the design of catalysts for hydrogen generation, as for the oxygen evolution process, it is necessary to ensure their protection against photocorrosion by composite formation or material coating. Moreover, it has been established that the materials for water splitting, should cover a range of potentials for oxidation $(+1.23 \mathrm{~V})$ and reduction $(0 \mathrm{~V})$ of water, with respect to the normal hydrogen electrode (NHE). However, if the goal is mainly the hydrogen generation, it is important to focus on the selectivity of the catalyst [115]. One such method is the creation of ternary catalysts e.g., Co-MOF based $\mathrm{Co} / \mathrm{CoN} / \mathrm{Co}_{2} \mathrm{P}$ or $\mathrm{NiCo}_{2} \mathrm{~S}_{4} / \mathrm{ZnIn}_{2} \mathrm{~S}_{4} / \mathrm{Co}_{3} \mathrm{O}_{4}$ composites [122,123]. Ternary photocatalysts are composed of three different materials that complement each other and generate multiphoton excitations. They can also utilize the heterojunction to drive electronic processes in the desired direction. In this way, photoexcitation of localized electronic states to achieve improved selectivity can be attained. On the technical side, the design and selection of the photoreactor have a major impact on selectivity of the process. Recently, the monolith reactor has attracted attention, instead of slurry, fluidized, fixed bed and optical fiber reactors. This is mainly characterized by a larger irradiation area and the use of photon energy, which increases hydrogen production [115].

While broadening the absorption spectrum of MOFs for more efficient light-harvesting is still in its infancy, one of the first approaches to achieve this was to exploit the energy transfer between ZIF-67 and the sensitizing chromophore RuN3 (cis-diisothiocyanatobis(2,2'-bipyridyl-4,4'-dicarboxylic acid) ruthenium(II)). Yang et al. [124] synthesized a ZIF-67 film with a UV-Vis spectrum containing spin-allowed d-d transition band at $585 \mathrm{~nm}$. In turn, for the obtained RuN3@ZIF-67 composite, additional absorption bands at 385 and $535 \mathrm{~nm}$ were noticed. Moreover, the energy transfer from the excited photosensitizer to the MOF occurs with an efficiency of $\sim 87 \%$. Such a system resulted in enhanced photoinduced absorption and ground state bleach recovery and, hence, ultimately led to an increase in water splitting and $\mathrm{H}_{2}$ evolution $\left(48.5 \mu \mathrm{mol} \mathrm{g}^{-1}\right)$. It is worth noting that the induction 
period for Co-MOFs was observed similarly to other photocatalytically active materials for hydrogen generation. The induction period is the reaction time window needed for hydrogen evolution. Depending on the catalyst and reaction conditions, the processes may differ in terms of hydrogen generation time. For RuN3@ZIF-67, the induction period was two hours before $\mathrm{H}_{2}$ evolution commences, thereby it can be considered as a limitation because it extends the process time.

ZIF-67 has been further investigated in sensitizing systems, but revealed better performance after specific modifications i.e., oxidation (O-ZIF-67), phosphating (P-ZIF-67), and sulfidizing (S-ZIF-67). ZIF-67 is known for its polyhedral particle morphology. Interestingly, each modification did not result in the loss of polyhedron shape. The modified ZIF-67 samples were characterized by increased catalytic activity in the process of hydrogen generation compared to unmodified ZIF-67. It was found that linkers can hinder the absorption of $\mathrm{H}^{+}$at the cobalt metal centres, thus their isolation can lead to a better catalytic performance. Taking P-ZIF-67 as an example, it is shown that free electron pairs are present in Co atoms ( $3 \mathrm{~d}$ orbital) and $\mathrm{P}$ atoms ( $3 \mathrm{p}$ orbital), ensuring easy electron transfer and protons absorption from the excited water molecules. At the same time, electrons can flow from the photosensitizer to the Co atoms, while $\mathrm{P}$ atoms absorb electrons from Co due to their stronger electronegativity. This resulted in increased electron density around the $\mathrm{P}$ and $\mathrm{Co}$ atoms, and the bi-active sites further boosted proton uptake and hydrogen production [125].

Gascon and co-workers [126] presented another way to significantly improve the catalytic activity of $\mathrm{NH}_{2}$-MIL-125(Ti) in the generation of hydrogen via its doping with cobalt species. The modification led to a 20 times more effective catalytic process compared to the pristine MOF, resulting in an external quantum efficiency of $0.5 \%$. It was suggested that cobaloxime is formed within the porous framework, although the specific structure of the cobalt species has not yet been elucidated. Meanwhile, the proposition mechanism was presented as follows: (i) at first, the linkers absorb photons, (ii) then, charge separation occurs to generate $\mathrm{Ti}^{3+}$, (iii) finally, a hole is generated in the linker. The electron deficiency causes the linker to react with an electron donor (triethylamine) and at the same time electrons are rapidly transferred to the cobalt. Consequently, it is reduced from $\mathrm{Co}^{\mathrm{III}}$ to $\mathrm{Co}^{\mathrm{II}}$ and becomes a highly active catalytic site, where $\mathrm{H}_{2}$ evolution occurs. Moreover, the Co@MOF composite displayed high TOF stability $\left(0.8 \mathrm{~h}^{-1}\right)$ after $65 \mathrm{~h}$ of continuous use, maintaining reusability without a significant decrease in the activity.

The nature of MOFs as coordination polymers forces researchers to increase their thermal, $\mathrm{pH}$, and solvent stability. In order to conduct catalytic reactions in aqueous solutions, they must be stable in water, which has been ensured in the case of the largely porous (50.7\%) $\mathrm{Co}_{3}-\mathrm{XL}$ of formula $\left\{\left[\mathrm{Co}_{3}\left(\mu_{3}-\mathrm{O}\right)(\mathrm{XL})_{3} \mathrm{Cl}_{3}\right] \mathrm{OH} \times 11.5 \mathrm{H}_{2} \mathrm{O}\right\}_{\mathrm{n}}$. It is a MOF composed of cobalt clusters [Co3 $\left.\left(\mu_{3}-\mathrm{O}\right)\right]$ and XL linker $\left(N, N^{\prime}\right.$-bicyclo [2.2.2]oct-7-ene-2,3,5,6-tetracarboxdiimide bi(1,2,4-triazole)), rich in uncoordinated carbonyl oxygen atoms. The material is distinguished by the two-fold interpenetrated MOFs formed by linkage between the nodes of the 6-c octahedral configuration and the catenated ligand. It results in two sets of identical $3 \mathrm{D}$ structures that are intertwined (Figure 9). Interestingly, $\mathrm{Co}_{3}-\mathrm{XL}$ proved to be capable of adsorbing water vapor $\left(192 \mathrm{~cm}^{3}\right)$, which increases the contact area between the reagent and the active sites in the water splitting process. MOF was additionally loaded with $\mathrm{Pt}$ as a co-catalyst, which was able to capture photoelectrons with a narrow band gap $(1.82 \mathrm{eV})$. At the same time, ethanol served as a sacrificial agent to compensate for the photogenerated holes. As result, $\mathrm{Co}_{3}-\mathrm{XL}$ showed $\mathrm{H}_{2}$ evolution of $23.05 \mu \mathrm{mol} \mathrm{g}^{-1} \mathrm{~h}^{-1}$, with better photocurrent than a single ligand and maintained solvent stability [127]. 


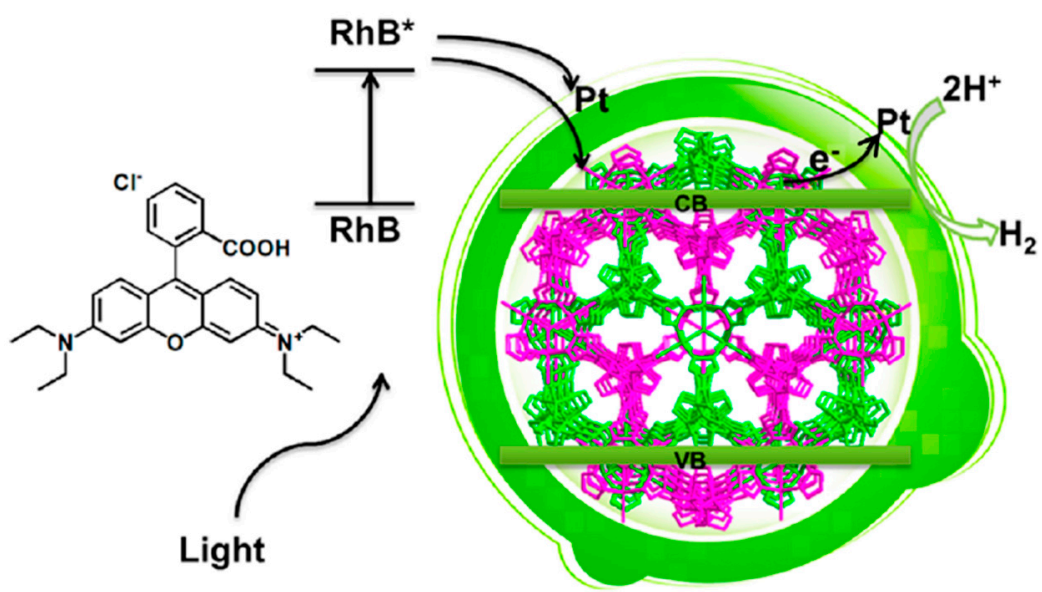

Figure 9. The photocatalytic mechanism of water splitting and hydrogen generation by $\mathrm{Co}_{3}-\mathrm{XL}$ with 2-fold interpenetrated MOFs (Reprinted with permission [127]. Copyright 2021 American Chemical Society).

No need for co-catalyst or co-sensitizer has been demonstrated in the unique ultrathin 2D nanosheets consisting of ruthenium sensitizer incorporated in MOF crystals with different inorganic building units. The sensitizing polypyridyl ruthenium complexes have favourable $\mathrm{HOMO} / \mathrm{LUMO}$ levels and long-lived excited states, which did not change distinctly after incorporation into MOF. The MOF nodes were $3 \mathrm{~d}$ transition-metal cations, of which the best hydrogen evolution efficiency indicated $\mathrm{Ni}^{2+}$ and $\mathrm{Co}^{2+}$. In the case of the Co-Ru system $\left(\mathrm{Co}_{0.5}\left[\mathrm{Ru}(\text { tpyCOO})_{2}\right] \mathrm{PF}_{6}\right)$, each Co cation coordinates with four carboxylate groups from linkers and forms a distorted tetrahedral geometry. The ruthenium linkers constitute a bridge between two metallic nodes, resulting in a 4-connected network with sql topology and rhombohedral topology of the 2D network. Interestingly, the sheets exhibited strong absorbance $(480 \mathrm{~nm})$ at acidic $\mathrm{pH}(3-5)$, which can be assigned to the metal-to-ligand charge transfer. The reduction in protons and $\mathrm{H}_{2}$ evolution occurred through the excited $\mathrm{Ru}$ linkers, yielding $589 \mu \mathrm{mol} \mathrm{g}{ }^{-1} \mathrm{~h}^{-1}$ and $923 \mu \mathrm{mol} \mathrm{g}{ }^{-1} \mathrm{~h}^{-1}$ of $\mathrm{H}_{2}$ for the $\mathrm{Co}-\mathrm{Ru}$ and $\mathrm{Ni}-\mathrm{Ru}$, respectively [128].

The great potential of MOFs and the methods available for their modification or enrichment with other compounds have contributed to their use as precursors for novel photoactive materials, for example, MOF-derived onion slice-type hollow cobalt sulfide nanostructures. A Co-MOF, composed of cobalt nodes and isophthalic acid linkers, was used as a template for the onion-like $\mathrm{Co}_{3} \mathrm{O}_{4}$, which was subsequently converted to $\mathrm{Co}_{4} \mathrm{~S}_{3}$ and doped with CdS nanoparticles. A MOF was utilized in this procedure due to its hollow structure, which allows a huge volume/mass reduction in $\mathrm{Co}_{4} \mathrm{~S}_{3}$ and onion slice shape formation. It provided a shorter path for the mass and charge transport in the $\mathrm{Co}_{4} \mathrm{~S}_{3} / \mathrm{CdS}$ composite during the $\mathrm{H}_{2}$ evolution process. The composite generated a much higher amount of $\mathrm{H}_{2}$ $\left(12,360 \mu \mathrm{mol} \mathrm{g}^{-1} \mathrm{~h}^{-1}\right)$ than pristine CdS $\left(450 \mu \mathrm{mol} \mathrm{g}^{-1} \mathrm{~h}^{-1}\right)$ [129].

In the photocatalytic reactions of water oxidation and water splitting, the main advantage of cobalt in MOF systems is its versatility (Table 2). Cobalt tends to form multiple oxo-clusters at nodes and has the ability to coordinate to various linkers forming unique complexes and stable MOFs. The materials with Co can be catalytically active, serve as semiconductors, or interact directly with solar energy as light-harvesters. Cobalt can be a metal node, a co-catalyst, an additive that increases charge separation, or an atom that acts as an electron transfer element to more catalytically active centres. Moreover, on the basis of presented reports, it has been proved that Co-based MOFs become more stable and can undergo many processes in aqueous solutions under various conditions. In addition, Co-MOFs and the materials derived from them can be easily recovered from the reaction system, which contributes to their high renewability. 
Table 2. Examples of Co-based MOFs, MOFs composites and MOF-derived materials used in the photo-driven water oxidation (PWO) for oxygen evolution and photoelectrocatalytic (PEC) water splitting for hydrogen generation.

\begin{tabular}{|c|c|c|}
\hline Photocatalyst & $\begin{array}{c}\text { TOF; TON; } \\
\text { Generated Product Amount }\end{array}$ & Ref. \\
\hline \multicolumn{3}{|c|}{ Phodo-driven water oxidation } \\
\hline ZIF-67 & $\mathrm{TOF}=0.035 \mathrm{~s}^{-11}$ & [24] \\
\hline $\mathrm{Co}_{4}-\mathrm{bdt}$ & $\mathrm{TOF}=3.050 \mathrm{~s}^{-1}$ & [100] \\
\hline$\left(\left[\mathrm{Co}{ }^{\mathrm{II}} \mathrm{Co}^{\mathrm{III}} \mathrm{W}_{11} \mathrm{O}_{39}\left(\mathrm{H}_{2} \mathrm{O}\right)\right]^{-7} @ \mathrm{MIL}-101\right.$ & $\mathrm{TOF}=0.48 \mathrm{~s}^{-1}$ & [101] \\
\hline$\left[\mathrm{Co}_{4}\left(\mathrm{PW}_{9} \mathrm{O}_{34}\right)_{2}\left(\mathrm{H}_{2} \mathrm{O}\right)_{2}\right]^{-10} @ \mathrm{MIL}-101$ & $\mathrm{TOF}=0.53 \mathrm{~s}^{-1}$ & [101] \\
\hline $\mathrm{Co}_{x} / \mathrm{MIL}-101$ & $\mathrm{TOF}=0.012 \mathrm{~s}^{-1}$ & {$[102]$} \\
\hline $\mathrm{P}_{2} \mathrm{~W}_{18} \mathrm{Co}_{4} @ \mathrm{MOF}-545$ & $\mathrm{TOF}=0.040 \mathrm{~s}^{-1}$ & [103] \\
\hline $\mathrm{P}_{2} \mathrm{~W}_{18} \mathrm{Co}_{4} @ \mathrm{MOF}-545$ film & $\mathrm{TON}=1600$ & [104] \\
\hline ZIF-67 & $9.8 \mu \mathrm{mol}$ of $\mathrm{O}_{2}$ & [105] \\
\hline Co-MOF-74@ZIF-67 & $15.0 \mu \mathrm{mol}$ of $\mathrm{O}_{2}$ & [105] \\
\hline Co-MOF-74 & $11.8 \mu \mathrm{mol}$ of $\mathrm{O}_{2}$ & [105] \\
\hline $\mathrm{CoP} @ \mathrm{CoO}_{\mathrm{x}}$ & $901.5 \mathrm{mmol} \mathrm{g}^{-1} \mathrm{~h}^{-1}$ of $\mathrm{O}_{2}$ & [112] \\
\hline \multicolumn{3}{|c|}{ Photoelectrocatalytic (PEC) water splitting for hydrogen generation } \\
\hline ZIF-67 film & $48.5 \mu \mathrm{mol} \mathrm{g}^{-1}$ of $\mathrm{H}_{2}$ & [124] \\
\hline $\mathrm{Co}_{x} / \mathrm{NH}_{2}-\mathrm{MIL}-125(\mathrm{Ti})$ & $\mathrm{TOF}=0.8 \mathrm{~h}^{-1}$ & [126] \\
\hline $\mathrm{Co}_{3}-\mathrm{XL}$ & $23.05 \mu \mathrm{mol} \mathrm{g}^{-1} \mathrm{~h}^{-1}$ of $\mathrm{H}_{2}$ & [127] \\
\hline$\left(\mathrm{Co}_{0.5}\left[\mathrm{Ru}\left(\mathrm{tpyCOO}_{2}\right] \mathrm{PF}_{6}\right)\right.$ & $589 \mu \mathrm{mol} \mathrm{g}^{-1} \mathrm{~h}^{-1}$ of $\mathrm{H}_{2}$ & [128] \\
\hline $\mathrm{Co}_{4} \mathrm{~S}_{3} / \mathrm{CdS}$ & $12360 \mu \mathrm{mol} \mathrm{g}^{-1} \mathrm{~h}^{-1}$ of $\mathrm{H}_{2}$ & [129] \\
\hline
\end{tabular}

\section{Photocatalytic Carbon Dioxide Reduction}

Carbon dioxide is one of the major greenhouse gases, the emission of which has been attempted to be reduced for decades $[130,131]$. Industrialization has notably contributed to the increase in the amount of $\mathrm{CO} 2$ in the atmosphere. Agriculture, transport, energy, and buildings are the main sources of $\mathrm{CO}_{2}$ emission. Despite many warnings, fossil fuels continue to be burned extensively. Even though restrictions have been implemented globally, a significant reduction in CO2 generation is far on the horizon [132-134]. Thereupon, efforts are being made to develop an efficient process for its conversion [135]. Photocatalytic reduction of $\mathrm{CO}_{2}$ seems to be an ideal solution, wherein this gas is captured and then converted into high-value compounds [136]. From a thermodynamic perspective, $\mathrm{CO}_{2}$ energy grade is low, therefore its conversion requires an energy contribution [137]. In the ongoing research on photocatalytic $\mathrm{CO}_{2}$ reduction, the main concern is the unsatisfactory reaction efficiency and the low selectivity of the obtained products. Moreover, in $\mathrm{CO}_{2}$ reduction, there is a high probability of water reduction and $\mathrm{H}_{2}$ evolution, which is a competing process. Regarding the fact that carbon in $\mathrm{CO}_{2}$ is in the highest possible oxidation state, it can be reduced to many different products (Figure 10). These are predominantly compounds with one carbon atom, such as $\mathrm{CO}, \mathrm{CH}_{4}, \mathrm{CH}_{3} \mathrm{OH}, \mathrm{HCHO}$, and $\mathrm{HCOOH}$. Products with two carbon atoms bonded (e.g., ethylene, acetylene, ethanol) are rare because it is difficult to stabilize single carbon radicals $[138,139]$. MOFs address many problems associated with photocatalytic processes due to their unique features. In the case of reaction with gases, $\mathrm{MOF}$ show high potential in $\mathrm{CO}_{2}$ capture [140]. If the high adsorption capacity is properly coupled with the photoelectrocatalytic properties of MOFs, it can result in high-performance materials [141]. The general mechanism of $\mathrm{CO}_{2}$ reduction with MOFs proceeds in the following manner. In the beginning, light excites a photosensitizer, which then undergoes reductive quenching by a sacrificial electron donor. The reduced photo- 
sensitizer donates its electrons to the MOF with adsorbed $\mathrm{CO}_{2}$. At this stage, the $\mathrm{CO}_{2}$ is reduced to $\mathrm{CO}_{2}{ }^{*}$. Subsequently, the $\mathrm{CO}_{2}{ }^{*}$ accepts protons generated from the decomposition of $\mathrm{H}_{2} \mathrm{O}$ and forms an $\mathrm{COOH}^{*}$ intermediate to be further reduced to $\mathrm{CO}^{*}$. Then, $\mathrm{CO}^{*}$ is desorbed, resulting in the formation of $\mathrm{CO}$ [48].

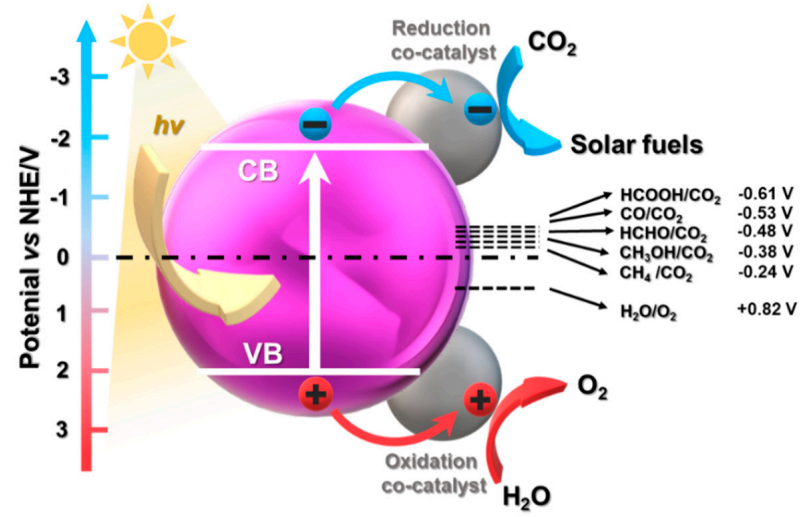

Figure 10. Scheme representing photocatalytic $\mathrm{CO}_{2}$ reduction process.

In the development of materials for $\mathrm{CO}_{2}$ reduction, systems capable of generating multielectrons are required [90]. For a MOF as a catalyst, the LUMO must be above the redox potential for the $\mathrm{CO}_{2}$ reduction half-reaction, which depends on the resulting product. For by far the most common $\mathrm{CO}_{2}$-to- $\mathrm{CO}$ conversion via Co-based MOF photocatalysts, the reduction potential is $-0.53 \mathrm{~V}$. By tuning the MOF composition, one can influence the optical and electronic responses i.e., HOMO and LUMO energy levels. In addition, the sorption capacity of the MOF is very important. Therefore, its textural parameters (e.g., surface area, pore volume) and improved affinity towards $\mathrm{CO}_{2}$ (e.g., by amine functionalities) must be attained in order to proceed efficient photoreduction [142]. For an effective $\mathrm{CO}_{2}$ conversion process, accessibility to the active sites is vital, thus $2 \mathrm{D}$ nanosheet MOFs with better exposed active sites are preferred. Defect engineering also contributes to improved access to nodes. Furthermore, defects play an important role in the excited state and charge relaxation pathways. Higher defect concentrations lead to longer excited-state lifetimes. This is attributed to the trapping of electrons in oxygen vacancies and holes in hydroxyl groups at the surface, which have been shown to play an important role in the $\mathrm{CO}_{2}$ reduction mechanism [143]. The conversion of $\mathrm{CO}_{2}$ can often lead to the formation of many products, but also to the generation of hydrogen from water. Therefore, it is quite challenging to design a material that has high selectivity for a single product without carrying out trial studies. The selectivity of $\mathrm{Co}-\mathrm{MOF}$ to receive one type of product in excess is still unclear. It requires a combination of theoretical calculations and the compilation of many parameters that represent a large system of variables during the process. In general, for any cobalt-based semiconductor, it is important to study the light intensity and photon energy, which must be applied to excite semiconductors. The photo-generated electrons and holes affect the kinetics of the reduction rate and ultimately the product selectivity. By attempting to select appropriate co-catalysts, it is possible to mitigate their effect on selectivity. Additionally, a key step is the desorption of the product from the material, which, if hindered, can result in low yields and poor selectivity. In photocatalytic $\mathrm{CO}_{2}$ conversion, it is necessary to couple a gas chromatography system equipped with a thermal conductivity detector (TCD), a hydrogen flame ionization detector (FID), and mass spectrometry to rigorously monitor the reaction products. By combining excitation features, catalyst and co-catalyst band structures, charge separation efficiency, and reactions on the material surface, it will be attainable to control product selectivity and material efficiency [138].

Cobalt-based complexes e.g., cobalt(II) tripodal or tetradentate ligand complexes, have been considered efficient catalysts of $\mathrm{CO}_{2}$ reduction with promising results in terms of high selectivity (95-100\%) [144,145]. Most importantly, MOFs are characterized by high $\mathrm{CO}_{2}$ 
sorption capacities, which could be a key aspect for the implementation of these materials on a larger scale. One of the highest $\mathrm{CO}_{2}$ adsorption capacities of $288 \mathrm{mg} \mathrm{g}^{-1}$ was reported for Co-MOF-74 and attributed to its well-developed surface area of $1314 \mathrm{~m}^{2} \mathrm{~g}^{-1}$ [146]. Therefore, the photocatalytic activities of $\mathrm{Co}-\mathrm{MOF}$ were tested in $\mathrm{CO}_{2}$ reduction process. For example, Co-based MOFs $\left[\mathrm{Co}_{2}(\mu-\mathrm{Cl})_{2}(\mathrm{bbta})\right],\left[\mathrm{Co}_{2}(\mu-\mathrm{OH})_{2}(\mathrm{bbta})\right],\left[\mathrm{Co}_{2}(\mu-\mathrm{OH})_{2}(\mathrm{btdd})\right]$

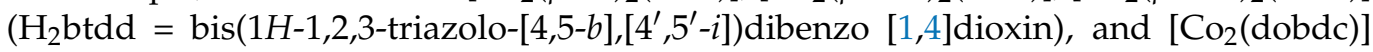
showed high photocatalytic efficiency in $\mathrm{CO}_{2}$ reduction. $\mathrm{Co}-\mathrm{MOF}$ with the $\mu-\mathrm{OH}^{-}$ligands adjacent to the open $\mathrm{Co}$ centres exhibited high selectivity to $\mathrm{CO}$ in the reaction under visible light $(420 \mathrm{~nm})$. The ligands acted as hydrogen bond donors and stabilized the primary $\mathrm{Co}-\mathrm{CO}_{2}$ adduct. They also provided protons to enable $\mathrm{C}-\mathrm{O}$ bond breaking. TOF of $\left[\mathrm{Co}_{2}(\mu-\mathrm{OH})_{2}(\mathrm{btdd})\right]$ had the highest value of $0.059 \mathrm{~s}^{-1}$, while maintaining high selectivity toward CO up to $98.2 \%$ [147].

Ye et al. [148] reported two composites-ZIF-67 with Zn-MOF and a dinuclear cobaltcomplex $\left[\mathrm{Co}_{2}(\mathrm{OH}) \mathrm{L}\right]\left(\mathrm{ClO}_{4}\right)_{3}\left(\mathrm{~L}=\mathrm{N}\left[\left(\mathrm{CH}_{2}\right)_{2} \mathrm{NHCH}_{2}\left(\mathrm{~m}-\mathrm{C}_{6} \mathrm{H}_{4}\right) \mathrm{CH}_{2} \mathrm{NH}\left(\mathrm{CH}_{2}\right)\right]_{3} \mathrm{~N}\right)$ with $\mathrm{Zn}$ MOF. The zinc-based MOF was applied as a photosensitizer. The cobalt complex and ZIF-67, both acted as co-catalysts present in the solution and accompanied the $\mathrm{CO}_{2}$ photoreduction to $\mathrm{CO}$ (Figure 11). They increased the formation of $\mathrm{CO}$ and the selectivity over $\mathrm{H}_{2}$ evolution. TONs and CO selectivity were 26.2, 78.9\% for the bulk Zn-MOF and 68.7, 81.5\% for ZnMOF/Co-complex. In the case of Zn-MOF/ZIF-67, values were the highest-117.8, 91.0\%. The photoelectrochemical impedance and photoluminescence studies suggest that the increased catalytic activity comes from the improved charge-transport capability, enhanced charge separation, and longer life duration of the photogenerated charge carriers.

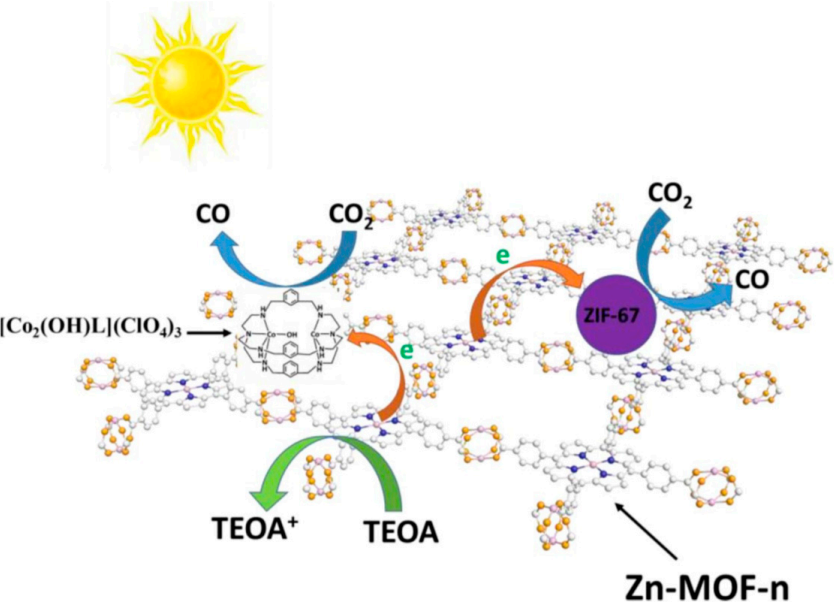

Figure 11. A MOF/Co-complex or MOF/ZIF-67 system for $\mathrm{CO}_{2}$ photoreduction with Zn-MOF nanosheets as the photosensitizer and Co-based materials as photocatalysts (Reprinted with permission [148]. Copyright 2018 Elsevier).

Porphyrin (POR) based MOFs with Co(II) as metal sites, showed 1.7 times higher photocatalytic performance in the $\mathrm{CO}$ formation $\left(0.4 \mu \mathrm{mol} \mathrm{g}{ }^{-1} \mathrm{~h}^{-1}\right)$ than corresponding Ni-POR. The structure of porphyrin boosts the absorption of visible light, similar to an antenna. Porphyrin units have the ability to propagate excitons and exhibit anisotropic energy transport across multiple struts from the originally excited strut [149]. The linkers are responsible only for light absorption, and the catalytic performance depends solely on the metallic Co nodes. The recombination rate of electron-hole pairs in Co-POR is lower than in the Ni-based MOF. The cobalt metallic sites provide various electron traps, and they also indicate higher $\mathrm{CO}_{2}$ adsorption energy of $17.92 \mathrm{~kJ} \mathrm{~mol}^{-1}\left(\mathrm{Ni}-\mathrm{POR} 16.37 \mathrm{~kJ} \mathrm{~mol}^{-1}\right)$. Consequently, $\mathrm{CO}_{2}$ was more easily activated to $\mathrm{CO}_{2}{ }^{*}$ on the Co-POR, than on the Ni-POR [150]. Porphyrin-based MOF-525-Co with atomically dispersed Co catalytic sites showed great enhancement of 3.13-fold in the evolution of $\mathrm{CO}\left(200 \mu \mathrm{mol} \mathrm{g}^{-1} \mathrm{~h}^{-1}\right)$, and 5.93-fold in $\mathrm{CH}_{4}$ generation $\left(36.67 \mu \mathrm{mol} \mathrm{g}{ }^{-1} \mathrm{~h}^{-1}\right)$ compared to the parent MOF. The pristine MOF-525 is a $\mathrm{Zr}$-based framework $\left(\mathrm{Zr}_{6} \mathrm{O}_{4}(\mathrm{OH})_{4}\left(\mathrm{TCPP}-\mathrm{H}_{2}\right)_{3}\right.$ with TCPP linkers [TCPP $=4,4^{\prime}, 4^{\prime \prime}, 4^{\prime \prime \prime}-$ 
(porphyrin-5,10,15,20-tetrayl)tetrabenzoate]. An increased $\mathrm{CO}_{2}$ reduction is related to the stronger affinity toward gaseous adsorbates after the metallization of pristine MOF-525. Interestingly, spectroscopic studies of single Co, MOF-525, and MOF-525-Co proved the presence of unique Co-N species in the doped MOF. Visible-light irradiation induced high-spin state $\mathrm{Co}^{\mathrm{II}}$ valence transformation to low-spin state $\mathrm{Co}^{\mathrm{I}}$. It was also found, that the coordination between the porphyrin ring and the Co sites most likely leads to efficient closure of the electron transfer channels from the porphyrin units to the Zr oxo-clusters [151].

A high TOF of 450 within $2.5 \mathrm{~h}$ upon conversion of $\mathrm{CO}_{2}$ to $\mathrm{CO}$ was observed for Co-ZIF-9 with cobalt clusters as nodes, and benzimidazolate as a linker. The reaction took place in the presence of $\left[\mathrm{Ru}(\mathrm{bpy})_{3}\right]^{2+}$ as photosensitizer under visible light $(420 \mathrm{~nm})$. CoZIF-9 exhibited catalytic activity in $\mathrm{CO}_{2}$ reduction immediately after synthesis. However, the micropores blocked by solvent guest molecules make activation in a vacuum necessary to increase channel accessibility. After opening the pores, the material can be applied in $\mathrm{CO}_{2}$ capture, concentration, and conversion with an efficiency of $83.6 \mu \mathrm{mol} \mathrm{h}^{-1}$ of $\mathrm{CO}$ evolution [152]. The catalytic activity of Co-ZIF-9 was further enhanced by integrating $\mathrm{MOF}$ with graphitic carbon nitride $\left(\mathrm{g}-\mathrm{C}_{3} \mathrm{~N}_{4}\right)$. The carbon material acted as a semiconductor photocatalyst, and $\mathrm{MOF}$ was a co-catalyst ensuring $\mathrm{CO}_{2}$ capture/concentration and stimulating light-induced charge separation in $\mathrm{CO}$ evolution. The quantum yield of the system under monochromatic light $(420 \mathrm{~nm})$ was $0.9 \%$, with TON reaching a value of 35 . A significant increase in the efficiency of photocatalytic $\mathrm{CO}_{2}$ reduction was noticed when various $\beta$-hydroxylated amines were added as electron donors. Among them, it was triethanolamine (TEOA) that caused the highest evolution of $\mathrm{CO}$, indicating a strong influence of steric hindrance even in the case of sacrificial electron donors in catalytic processes [153].

The Co-ZIF-9, being simultaneously a catalyst and a co-catalyst, supported CdS in $\mathrm{CO}_{2}$ reduction and promoted electron transfer. The composite showed a high apparent quantum yield $(1.93 \%)$. In the proposed reaction mechanism, visible light generated electron-hole pairs on the semiconductor. Then, the electrons migrated to the conduction band of $\mathrm{CdS}$ and were transferred to the $\mathrm{CO}_{2}$ adsorbed by the MOF. Benzimidazole linkers stabilized the $\mathrm{CO}_{2}$ * intermediates, which during the continuous reduction and mediating support of cobalt species formed CO [154]. Zhong and co-workers [155] described a PSM of Co-MOF with a double-linker framework composition: 4,5-dicarboxylic acid and 4,4'bipyridine. The pristine $\mathrm{Co}-\mathrm{MOF}$ revealed good catalytic activity in $\mathrm{CO}_{2}$ reduction but with unsatisfactory selectivity. However, its performance was increased by a bimetallic strategy, in which $2 / 3$ of the $\mathrm{Co}$ (II) was replaced by $\mathrm{Ni}$ (II). Ultimately, the formation of $\mathrm{CO}$ catalysed in the presence of the bimetallic MOF, reached up to $1160 \mu \mathrm{mol} \mathrm{g}^{-1} \mathrm{~h}^{-1}$. The selectivity of the process toward CO was also excellent with $94.6 \%$ over $\mathrm{H}_{2}$.

A robust and low-cost catalyst was prepared by Lu and co-workers [156] via Co-MOF $2 \mathrm{D}$ layers carbonization with subsequent anchoring of single-Co(II) sites. The efficiency of $\mathrm{CO}_{2}$-to-CO photocatalytic conversion was 222 times higher $\left(464.1 \mu \mathrm{mol} \mathrm{g}{ }^{-1} \mathrm{~h}^{-1}\right)$ for the composite than for the bulky Co-MOF. The reaction was carried out in a $\mathrm{CH}_{3} \mathrm{CN} / \mathrm{H}_{2} \mathrm{O}$ solution in the presence of TEOA as a sacrificial reducing agent. Tests of the photocurrent response revealed intense current generation caused by light irradiation (420 nm). The energy of photons triggered the migration of electrons to the surface of the composite, followed by electron transfer to the active $\mathrm{Co}(\mathrm{II})$ sites with $\mathrm{CO}_{2}$ already adsorbed.

A similar efficiency of $\mathrm{CO}_{2}$ reduction but toward $\mathrm{HCOO}^{-}$generation $\left(456 \mu \mathrm{mol} \mathrm{g} \mathrm{g}^{-1} \mathrm{~h}^{-1}\right)$ was achieved by the trinuclear $\mathrm{Co}^{\mathrm{II}} \mathrm{Co}^{\mathrm{II}} \mathrm{Co}^{\mathrm{II}} \mathrm{MOF}$ with a band gap of $2.95 \mathrm{eV}$. The Co-MOF

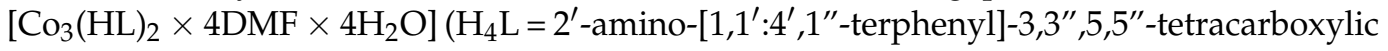
acid) exhibited $\mathrm{CO}_{2}$-reductive abilities in the presence of BNAH (1-benzyl-1,4dihydronicotinamide) as the electron donor. Photoinduced electron transition (PET) was investigated, and single electron transfer was established in the trinuclear clusters. One electron was transferred from $\left[\mathrm{Ru}(\mathrm{bpy})_{3}\right]^{2+}$ to $\mathrm{Co}-\mathrm{MOF}$, as follows: $\left[\mathrm{Co}^{\mathrm{II}} \mathrm{Co}^{\mathrm{II}} \mathrm{Co}^{\mathrm{II}}\right]$ to $\left[\mathrm{Co}^{\mathrm{I}} \mathrm{Co}^{\mathrm{II}} \mathrm{Co}^{\mathrm{II}}\right]$ and from $\left[\mathrm{Co}^{\mathrm{I}} \mathrm{Co}^{\mathrm{II}} \mathrm{Co}^{\mathrm{II}}\right]$ to $\left[\mathrm{Co}^{\mathrm{I}} \mathrm{Co}^{\mathrm{II}} \mathrm{Co}^{\mathrm{I}}\right]$. This dynamic trinuclear system acted as the catalytically active sites responsible for $\mathrm{CO}_{2}$ reduction (Figure 12) [157]. 


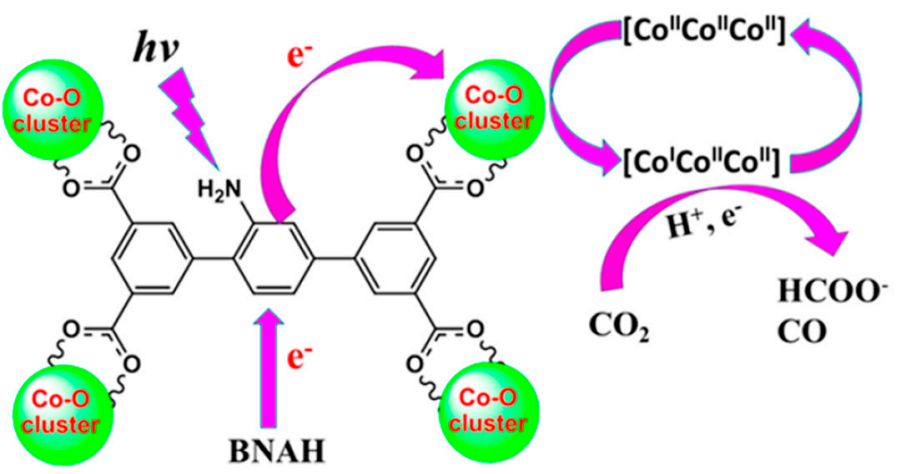

Figure 12. The mechanism of photocatalytic $\mathrm{CO}_{2}$ reduction to $\mathrm{HCOO}^{-}$and $\mathrm{CO}$, in the presence of amine-functionalized $\mathrm{Co}-\mathrm{MOF}\left[\mathrm{Co}_{3}(\mathrm{HL})_{2} \times 4 \mathrm{DMF} \times 4 \mathrm{H}_{2} \mathrm{O}\right]$ as catalyst and BNAH (1-benzyl-1,4dihydronicotinamide) as electron donor (Reprinted with permission [157]. Copyright 2018 American Chemical Society).

The rhombic dodecahedral ZIF-67 was applied as a co-catalyst to generate $\mathrm{CO}$ from $\mathrm{CO}_{2}$. The reaction was conducted under visible light and in the presence of a typical ruthenium-based photosensitizer. Surprisingly, $\mathrm{CO}_{2}$ reduction proceeded even with the small amount of ZIF-67 $(0.05 \mathrm{mg})$, resulting in the generation of $32.7 \mu \mathrm{mol}$ of $\mathrm{CO}$. The material indicated TON of 112 for $\mathrm{CO}_{2}$ reduction after $30 \mathrm{~min}$. To emphasize the specific function of cobalt species spatially coordinated to imidazolate motifs to reduce $\mathrm{CO}_{2}$, identical reactions were conducted with Zn-ZIF-8, Cu-HKUST-1, Zr-UiO-66- $\mathrm{NH}_{2}$, and Fe-MIL-101-NH $\mathrm{NH}_{2}$. Other non-cobalt based MOFs were not photocatalytically active in $\mathrm{CO}_{2}$ conversion, proving that cobalt sites are irreplaceable in photocatalytic electron mediation [158]. The light-driven $\mathrm{CO}_{2}$ reduction in ZIF-67 was further investigated to increase its effectiveness by using $\mathrm{TiO}_{2}$ as a shell. An amorphous $\mathrm{TiO}_{2}\left(\mathrm{a}-\mathrm{TiO}_{2}\right)$ layer was uniformly deposited on the MOF surface, which successfully prevented the photocorrosion of ZIF-67. Moreover, the ZIF-67@a- $-\mathrm{TiO}_{2}$ composite reduced $\mathrm{CO}_{2}$ to $\mathrm{CO}$, giving $43.8 \mu \mathrm{mol}$ of $\mathrm{CO}$ after $4 \mathrm{~h}$ under light with $67.2 \%$ selectivity over $\mathrm{H} 2$. The hydrophilic properties of the metal oxide caused the material to absorb $\mathrm{H}_{3} \mathrm{O}^{+}$, which decreased the competition between $\mathrm{CO}_{2}$ and $\mathrm{H}_{3} \mathrm{O}^{+}$adsorption on $\mathrm{ZIF}-67$. The a-TiO ${ }_{2}$ layer improved the light-harvesting efficiency by enhancing light scattering, but it also improved the charge transfer between photosensitizer and MOF. In addition, the mesoporous properties of a- $\mathrm{TiO}_{2}$ facilitated mass diffusion without impairing $\mathrm{CO}_{2}$ adsorption [159]. A remarkable result of a billion-fold enhancement in the conductivity of ZIF-67 composites with polypyrrole (PPy) was presented by Peng and co-workers [160]. The morphology of ZIF-67 was controlled by modulating the coordination during the stepwise addition of pyrrole monomers. PPy-reinforced ZIF-67 ensembles can be changed from rhombic dodecahedra to cubes. The obtained materials exhibited high chemical stability with retained photocatalytic capabilities for $\mathrm{CO}_{2}$ reduction This high enhancement in the conductivity of PPy-ZIF-67 was attributed to the PPy polymer network in the MOF and also on its surface. In the typical photocatalytic system with $\left[\mathrm{Ru}(\mathrm{bpy})_{3}\right]^{2+}$ and TEOA, the composite reduced $\mathrm{CO}_{2}$ and $59.42 \mu \mathrm{mol}$ of $\mathrm{CO}$ was generated. The increased efficiency compared to pure ZIF- 67 is an outcome of the $\pi-\pi$ interaction between the polymer and the photosensitizer, which enhances the static electron transfer to the catalyst. A charge transfer model was established, where light-induced electrons in the photosensitizer hop to LUMO at $3.19 \mathrm{eV}$. Subsequently, electrons are delocalized from $\pi^{*}$ orbital and transferred by PPy to the ZIF-67 conduction band at $3.76 \mathrm{eV}$. Since the ZIF-67 conduction band minimum (CBM) is higher than the redox potential of the $\mathrm{CO}_{2}$-to- $\mathrm{CO}$ conversion $(3.91 \mathrm{eV})$, the electron can easily participate in the photocatalytic reduction of $\mathrm{CO}_{2}$ (Figure 13). Moreover, the catalyst was recycled 4 times, whereas ZIF-67 was applied only once. 
A

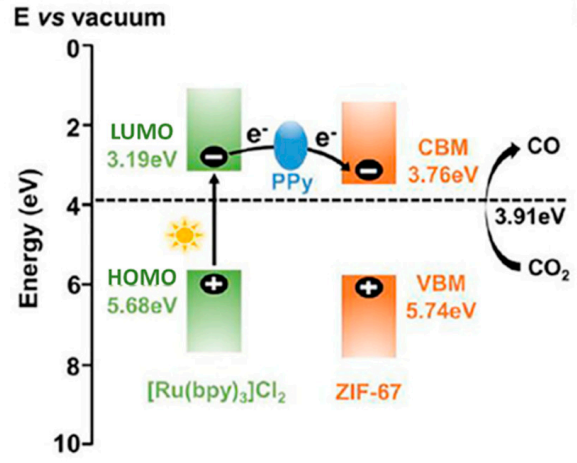

B

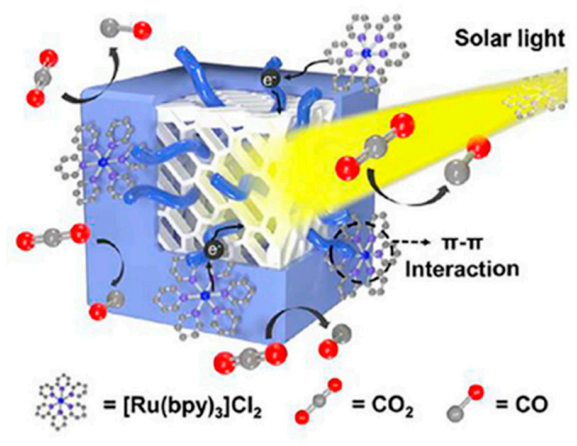

Figure 13. Scheme representing (A) the band levels and electron transfer among the $\left[\mathrm{Ru}(\mathrm{bpy})_{3}\right]^{2+}$ photosensitizer, ZIF-67@PPy co-catalyst, and $\mathrm{CO}_{2} / \mathrm{CO}$ redox pair. On the right $(\mathbf{B})$ the photocatalytic $\mathrm{CO}_{2}$ reduction process on the cubic ZIF-67@PPy composite in the presence of $\left[\mathrm{Ru}(\mathrm{bpy})_{3}\right]^{2+}($ Reprinted with permission [160]. Copyright 2021 Elsevier).

Photocatalytic reduction of carbon dioxide is an immensely important research topic, in which out of all MOFs, those based on cobalt are taking the lead. The Co active sites are a much more cost-effective alternative to noble metals. Their coupling with the highly porous structure of MOFs provides a promising base material for $\mathrm{CO}_{2}$ adsorption and reduction (Table 3). Moreover, the extensive modification possibilities of MOFs contribute to highly selective conversion of $\mathrm{CO}_{2}$, mainly to $\mathrm{CO}$. The biggest limitation of cobalt-based MOFs is that compounds with only one carbon atom are obtained after reduction of $\mathrm{CO}_{2}$. The main challenge, which has not yet been overcome is to obtain more complex $\mathrm{C}-\mathrm{C}$ compounds such as hydrocarbons.

Table 3. Examples of Co-based MOFs used in the photocatalytic $\mathrm{CO}_{2}$-to-CO conversion.

\begin{tabular}{|c|c|c|c|}
\hline Photocatalyst & $\begin{array}{c}\text { TOF; TON; } \\
\text { Generated Product Amount }\end{array}$ & $\begin{array}{l}\text { Selectivity over } \mathrm{H}_{2} \\
\text { Evolution }\end{array}$ & Ref. \\
\hline$\left[\mathrm{Co}_{2}(\mu-\mathrm{OH})_{2}(\mathrm{btdd})\right]$ & $\mathrm{TOF}=0.059 \mathrm{~s}^{-1}$ & $98.2 \%$ & [147] \\
\hline Zn-MOF/Co-complex & $\mathrm{TON}=68.7$ & $81.5 \%$ & [148] \\
\hline Zn-MOF /ZIF-67 & $\mathrm{TON}=117.8$ & $91.0 \%$ & [148] \\
\hline Co-POR & $0.4 \mu \mathrm{mol} \mathrm{g}{ }^{-1} \mathrm{~h}^{-1}$ of $\mathrm{CO}$ & - & [149] \\
\hline MOF-525-Co & $\begin{array}{c}200 \mu \mathrm{mol} \mathrm{g}^{-1} \mathrm{~h}^{-1} \text { of } \mathrm{CO} \\
36.67 \mu \mathrm{mol} \mathrm{g}^{-1} \mathrm{~h}^{-1} \text { of } \mathrm{CH}_{4}\end{array}$ & - & [151] \\
\hline Co-ZIF-9 & $\begin{array}{l}\text { TOF }=450 \text { within } 2.5 \mathrm{~h} \\
83.6 \mu \mathrm{mol} \mathrm{h}{ }^{-1} \text { of } \mathrm{CO}\end{array}$ & - & [152] \\
\hline g-C ${ }_{3} \mathrm{~N}_{4} @$ Co-ZIF-9 & $\mathrm{TON}=35$ & - & [153] \\
\hline Cd@Co-ZIF-9 & $85.6 \mu \mathrm{mol}$ of $\mathrm{CO}$ & $91.2 \%$ & [154] \\
\hline $\mathrm{Co}_{1} \mathrm{Ni}_{2}-\mathrm{MOF}$ & $1160 \mu \mathrm{mol} \mathrm{g}^{-1} \mathrm{~h}^{-1}$ of $\mathrm{CO}$ & $94.6 \%$ & {$[155]$} \\
\hline $\mathrm{Co}-\mathrm{C}_{3} \mathrm{~N}_{4}$ & $464.1 \mu \mathrm{mol} \mathrm{g}^{-1} \mathrm{~h}^{-1}$ of $\mathrm{CO}$ & - & [156] \\
\hline trinuclear $\mathrm{Co}^{\mathrm{II}} \mathrm{Co}^{\mathrm{II}} \mathrm{Co}^{\mathrm{II}} \mathrm{MOF}$ & $456.0 \mathrm{mmol} \mathrm{g}^{-1} \mathrm{~h}^{-1}$ of $\mathrm{HCOO}^{-}$ & 61 & [157] \\
\hline ZIF-67 & $\begin{array}{c}\mathrm{TON}=112 \\
32.7 \mu \mathrm{mol} \text { of } \mathrm{CO}\end{array}$ & - & [158] \\
\hline ZIF-67@a-TiO 2 & $43.8 \mu \mathrm{mol}$ of $\mathrm{CO}$ & $67.2 \%$ & [159] \\
\hline PPy-ZIF-67 & $59.42 \mu \mathrm{mol}$ of $\mathrm{CO}$ & - & [160] \\
\hline
\end{tabular}

\section{Photocatalytic Oxidation of Organic Compounds}

Recently, huge amounts of dangerous organic contaminants e.g., biphenyls or phenols that are generated in diverse industries enter water reservoirs threatening wildlife and 
people. Due to the fact that these compounds are non-biodegradable and stable, photocatalytic oxidation processes as an effective method for eliminating resistant pollutants are applied. Besides low energy consumption, mild conditions of the reaction, and broad scope of applications, with this strategy organic contaminants can be decomposed into biodegradable and less toxic molecules or mineralized into carbon dioxide and water. Furthermore, photocatalytic oxidation may be utilized to obtain intermediates that are subsequently used for synthesizing valuable compounds e.g., drugs [161]. Conducting the reactions under light irradiation allows to avoid using high temperatures and consequently unwanted by-products [162]. Cobalt-based MOFs display great photocatalytic performance in oxidation reactions, which results from the activity of cobalt ions, thus they are readily used [39]. The low selectivity is the main limiting factor that has an influence on reaction efficiency. Despite putting great efforts into proving the feasibility, photocatalytic oxidation of organic compounds is often a non-selective process. For this reason, it is crucial to apply photocatalysts, such as Co-MOFs, to obtain products with high selectivity [163].

Hollow structural Co-MOF-74 ( $h$-Co-MOF-74) possessing a thin shell ( $\sim 50 \mathrm{~nm})$ assembled by ultra-small nanoparticles $(8-18 \mathrm{~nm})$ was synthesized and applied in thioanisole oxidation to obtain methyl phenyl sulfoxide (a crucial intermediate for the pharmaceuticals syntheses) [164]. This unique structure carries numerous benefits including high specific surface area, abundant oxygen vacancies, improved ability of light absorption, and easily accessible catalytic active sites. Owing to these properties, the full conversion of thioanisole with $99 \%$ selectivity toward methyl phenyl sulfoxide was achieved in ten hours under simulated sunlight irradiation. Almost identical results ( $99 \%$ conversion and $98 \%$ selectivity) were obtained after the fifth reuse cycle. In addition, $h$-Co-MOF-74 has also been used in the photocatalytic oxidation of 4-bromothioanisole, 4-fluorobenzaldehyde, methyl p-tolyl sulphide, alongside 4-chlorothioanisole. For each of them, $100 \%$ conversion to proper products and over $97 \%$ selectivity were observed.

Cobalt(II) was introduced into the metal-organic framework TMU-22(Zn) through post-synthetic exchange, forming the mixed-metal TMU-22(Zn/Co) subsequently applied in benzyl alcohol oxidation to benzaldehyde [165]. Three hours of visible light irradiation yielded $65 \%$ efficiency, while with the TMU-22(Zn) only 25\% conversion was reported. $\mathrm{Co}^{2+}$ ions were profitably substituted in the framework at more available positions toward the substrate, hence the catalytic performance was improved. According to the reaction mechanism, the exchange between $\mathrm{Co}^{2+}$ and $\mathrm{Zn}^{2+}$ resulted in the development of a new level in the conduction band. Thereby, the electrons from the valence band may be promoted to this level and, as a consequence, the band gap is narrowed. Cobalt also acts as a trap immobilizing electron, which is then transferred to $\mathrm{O}_{2}$ generating highly oxidative $-\mathrm{O}_{2}{ }^{-}$. Subjected to five oxidation cycles, TMU-22( $\mathrm{Zn} / \mathrm{Co}$ ) showed $54 \%$ effectiveness which indicates the possibility of its reuse. Furthermore, the conducted leaching test confirmed the stability of the photocatalyst. Despite the satisfying performance of TMU-22(Zn/Co) in the conversion of benzyl alcohol, the yields obtained after the oxidation of the electrondeficient substrates (e.g., 4-nitobenzyl alcohol) were lower (40\%). The reason might be the structure of the derivative with a steric hindrance.

Effective catalyst-magnetic core/shell metal-organic framework $\mathrm{Fe}_{3} \mathrm{O}_{4} @ \mathrm{Ni}-\mathrm{Co}-\mathrm{BDC}$ NPs has been applied in the selective aerobic oxidation of benzyl alcohol under solar light irradiation [162]. In three hours, $87 \%$ conversion to the proper carbonyl product was observed, whereas in the case of $\mathrm{Fe}_{3} \mathrm{O}_{4} @ \mathrm{Ni}-\mathrm{BDC}$ NPs or $\mathrm{Fe}_{3} \mathrm{O}_{4} @ \mathrm{Co}-\mathrm{BDC}$ NPs the reaction was slower and not as efficient $(60 \%, 45 \%)$. The differences can be attributed to the high band gap of $\mathrm{Fe}_{3} \mathrm{O}_{4} @ \mathrm{Ni}-\mathrm{BDC}$ NPs and $\mathrm{Fe}_{3} \mathrm{O}_{4} @$ @o-BDC NPs, thus more UV light is needed for their activation. In order to check the reusability of the $\mathrm{Fe}_{3} \mathrm{O}_{4} @ \mathrm{Ni}-\mathrm{Co}-\mathrm{BDC}$ NPs photocatalyst, seven recycling experiments were carried out. The results showed that it can be recycled without a noticeable decrease in activity. This strategy may be expanded to the wide range of substrates such as primary and secondary benzylic, in addition to aliphatic alcohols, achieving great conversion and selectivity toward corresponding 
aldehydes or ketones. In the oxidation of 4-methylbenzyl alcohol, 4-methoxybenzyl alcohol, and 3-methoxybenzyl alcohol the conversion yields were as follows: 93\%, 98\%, 90\%.

Another magnetic nanocomposite that can be applied in the oxidation of alcohols to aldehydes under visible light irradiation is $\mathrm{CoFe}_{2} \mathrm{O}_{4} / \mathrm{Ce}-\mathrm{UiO}-66$ [166]. Coupling a MOF with a cobalt ferrite can enhance the photocatalytic performance as well as stability and recyclability. $\mathrm{CoFe}_{2} \mathrm{O}_{4}$ possesses superparamagnetic properties, thanks to which Co-ferrite/MOF can be regenerated by adding the external magnetic field. To examine the $\mathrm{CoFe}_{2} \mathrm{O}_{4} / \mathrm{Ce}-\mathrm{UiO}-66$ catalytic activity, it was used in the oxidation of $n$-hexanol and compared with $\mathrm{CoFe}_{2} \mathrm{O}_{4}$ and $\mathrm{Ce}-\mathrm{UiO}-66$ (Figure 14A). The synthesized composite exhibited $\sim 80 \%$ conversion of alcohol in four hours, which was higher than that obtained with $\mathrm{CoFe}_{2} \mathrm{O}_{4}$ and $\mathrm{Ce}-\mathrm{UiO}-66$ (Figure 14B). The relatively low yield is due to the fact that aliphatic alcohols oxidation is more difficult than aromatic ones which are easily transformed to aldehydes. The reuse studies showed that $\mathrm{CoFe}_{2} \mathrm{O}_{4} / \mathrm{Ce}-\mathrm{UiO}-66$ can be utilized at least five times without significant activity loss. This MOF was also applied in the six-hour oxidation of aromatic alcohols including 3-nitrobenzyl alcohol, 4-nitrobenzyl alcohol, and 4-bromobenzyl alcohol. The corresponding aldehydes (3-nitrobenzaldehyde, 4-nitrobenzaldehyde, 4-bromobenzaldehyde) were obtained with $90 \%, 90 \%$, and $82 \%$ efficiencies, respectively.
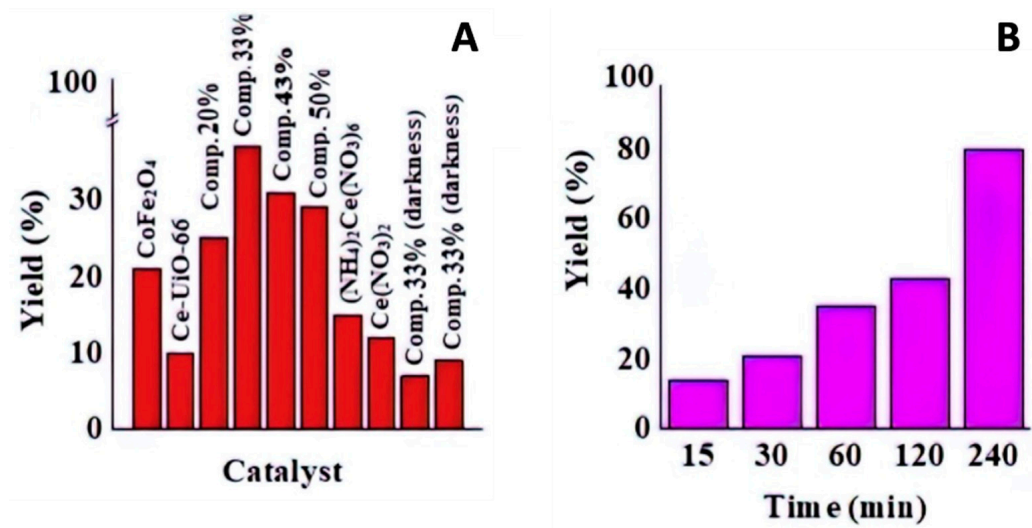

Figure 14. Graphs of $n$-hexane oxidation yield vs.: (A) applied catalyst (B) reaction time (Reprinted with permission [166]. Copyright 2021 Elsevier).

Metal-organic framework/carbon nitride nanosheets composite-TMU-49/CNNSs $\left(\mathrm{TMU}-49=[\mathrm{Co}(\mathrm{oba})(\mathrm{bpfb})] \times(\mathrm{DMF})_{2} ; \mathrm{bpfb}=N, N^{\prime}\right.$-(1,4-phenylene)-diisonicotinamide $)$ has been obtained and utilized as a visible light-active catalyst for benzyl alcohol oxidation [167]. Through linking a MOF with $\mathrm{C}_{3} \mathrm{~N}_{4}$, the benefits of their complementary features while restraining the recombination rate of electron-hole were achieved. After three hours, TMU49/CNNSs exhibited 78\% conversion, whereas for the TMU-49 and CNNSs the efficiency was much lower $(36 \%, 16 \%)$. Four hours of oxidation yielded an even higher conversion $(81 \%)$ to benzaldehyde with $75 \%$ selectivity. The light source turned out to also affect the reaction. As the conversion of both reactions was alike, the selectivity under UV and visible irradiation were as follows: $52 \%$ and $69 \%$. The synthesized composite was subjected to five recycles which showed that TMU-49/CNNSs retained its photocatalytic activity. Moreover, the material was also applied in the oxidation of a few benzyl alcohol derivatives. Efficiencies of $83 \%, 91 \%, 76 \%$, and $45 \%$ were observed for 4-nitrobenzyl alcohol, 4-bromobenzyl alcohol, 4-methylbenzyl alcohol, and 4-methoxybenzyl alcohol, respectively. According to the proposed mechanism, under visible light electron-hole pairs may be formed by the excited TMU-49 and CNNSs (Figure 15). Electrons in the TMU-49 conduction band are transferred to the CNNSs valence band to recombine with the holes. Thereby, the subsequent accumulation of electrons in the CNNSs conduction band triggers the $\mathrm{O}_{2}$ reduction to $\bullet \mathrm{O}_{2}{ }^{-}$. The holes in the TMU-49 valence band can oxidize alcohols in the meantime. As a consequence, TMU-49/CNNSs exhibit excellent photocatalytic performance toward alcohols. 


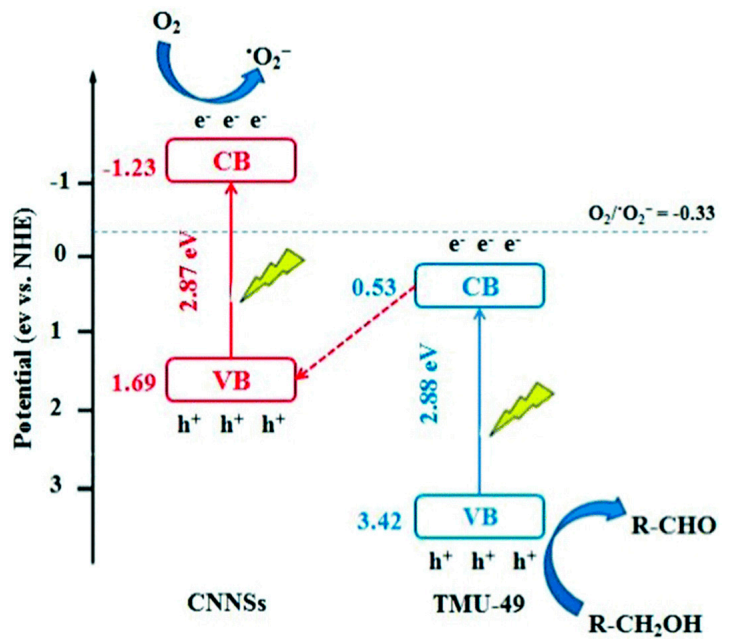

Figure 15. Schematic view of the alcohol oxidation mechanism (Reprinted with permission [167]. Copyright 2021 The Royal Society of Chemistry).

In summary, the application of Co-based MOFs as photocatalysts in the oxidation of numerous alcohols and other organic compounds to corresponding products has been described. Under light irradiation, these materials enable high conversion efficiencies, in addition to selectivity, hence they are gaining more and more attention (Table 4 ). With the use of Co-MOFs, the oxidation processes can be carried out in mild conditions. The products of this reaction may be applied in the synthesis of e.g., drugs and cosmetics. Furthermore, by decomposition of diverse organic pollutants, less harmful and more easily biodegradable compounds are produced, therefore MOFs may be utilized in removing resistant contaminants from water. Considering the availability, high activity, satisfactory stability, and efficiency of cobalt MOFs as well as their reusability without a significant decrease in the catalytic performance, these materials display excellent potential in the oxidation of organic compounds.

Table 4. Examples of Co-based MOFs used in the photocatalytic oxidation of various organic compounds.

\begin{tabular}{|c|c|c|c|c|}
\hline Photocatalyst & Compound & $\begin{array}{c}\text { Conversion } \\
\text { Efficiency [\%] }\end{array}$ & Time & Ref. \\
\hline \multirow{4}{*}{$\mathrm{Fe}_{3} \mathrm{O}_{4} @ \mathrm{Ni}-\mathrm{Co}-\mathrm{BDC} \mathrm{NPs}$} & Benzyl alcohol & 87 & $3 \mathrm{~h}$ & \multirow{4}{*}{ [162] } \\
\hline & 4-methylbenzyl alcohol & 93 & $3 \mathrm{~h}$ & \\
\hline & 4-methoxybenzyl alcohol & 98 & $3 \mathrm{~h}$ & \\
\hline & 3-methoxybenzyl alcohol & 90 & $3 \mathrm{~h}$ & \\
\hline \multirow{5}{*}{$h$-Co-MOF-74 } & Thioanisole & 100 & $10 \mathrm{~h}$ & \multirow{5}{*}{ [164] } \\
\hline & 4-bromothioanisole & 100 & $10 \mathrm{~h}$ & \\
\hline & 4-fluorobenzaldehyde & 100 & $10 \mathrm{~h}$ & \\
\hline & Methyl p-tolyl sulphide & 100 & $10 \mathrm{~h}$ & \\
\hline & 4-chlorothioanisole & 100 & $10 \mathrm{~h}$ & \\
\hline TMU-22(Zn/Co) & Benzyl alcohol & 65 & $3 \mathrm{~h}$ & [165] \\
\hline \multirow{4}{*}{$\mathrm{CoFe}_{2} \mathrm{O}_{4} / \mathrm{Ce}-\mathrm{UiO}-66$} & n-hexanol & $\sim 80$ & $4 \mathrm{~h}$ & \multirow{4}{*}{ [166] } \\
\hline & 3-nitrobenzyl alcohol & 90 & $6 \mathrm{~h}$ & \\
\hline & 4-nitrobenzyl alcohol & 90 & $6 \mathrm{~h}$ & \\
\hline & 4-bromobenzyl alcohol & 82 & $6 \mathrm{~h}$ & \\
\hline \multirow{5}{*}{ TMU-49/CNNSs } & Benzyl alcohol & 81 & $4 \mathrm{~h}$ & \multirow{5}{*}{ [167] } \\
\hline & 4-nitrobenzyl alcohol & 83 & $3 \mathrm{~h}$ & \\
\hline & 4-bromobenzyl alcohol & 91 & $3 \mathrm{~h}$ & \\
\hline & 4-methylbenzyl alcohol & 76 & $3 \mathrm{~h}$ & \\
\hline & 4-methoxybenzyl alcohol & 45 & $3 \mathrm{~h}$ & \\
\hline
\end{tabular}




\section{Conclusions}

This review shows the enormous application potential of cobalt-based MOFs and their composites in photocatalytic processes including dye degradation, water and organic compound oxidation, and $\mathrm{CO}_{2}$ reduction. These materials are characterized by high porosity, which can expose more cobalt active sites, promote transport of reaction substrates and products, as well as reduce carrier transport distance, thereby inhibiting photogenic electron holes recombination. Both the metallic nodes and linkers of MOFs can be subjected to a wide variety of modifications in order to constitute efficient light absorption centres. Interestingly, a MOFs' porous structure enables the incorporation of photosensitizers and co-catalysts to promote carrier separation and enhance photocatalytic activity. Moreover, their high crystallinity prevents the formation of structural defects resulting from the rapid recombination of electron holes. Cobalt-based MOFs show high catalytic efficiency in light-driven reactions as they can be semiconductors or directly interact with solar energy as light harvesters. Cobalt active sites ensure different electron traps that facilitate electrons and holes separation. In addition, they can cause a longer electron lifetime in the photocatalytic processes.

Cobalt species have different functions in each process described in the review, therefore they were presented separately. Considering the mechanisms of the reactions, various active forms are involved in dye degradation, water oxidation and splitting, carbon dioxide reduction, and organic compounds oxidation. In the photodegradation of colorants, mainly $\bullet \mathrm{OH}$ radicals are responsible for their decomposition. Highly oxidative $\bullet \mathrm{O}_{2}{ }^{-}$affects the oxidation of organic compounds. In these reactions, conversion yields and selectivity provide information about the effectiveness of the catalyst. The conductivity of cobalt-based MOFs is important for the oxidation-reduction reactions of water splitting. The photocatalytic activity depends on the ability of electron and hole separation, and their recombination. The light absorption capabilities control the photocatalytic activity, therefore linkers that can harvest light in a broad spectrum are desired. A similar relationship is observed for $\mathrm{CO}_{2}$ reduction processes. Here, in turn, the key role plays the ability of $\mathrm{MOF}$ to adsorb $\mathrm{CO}_{2}$ on the surface. The structure of MOF and accessibility to active catalytic centres determine the type of generated product and selectivity of the process. The photocatalytic activity of cobalt-based MOFs in the above-mentioned applications does not yet satisfy the high expectations of the industry; they have actual utility in small-scale systems. The optimization of both the costs of linkers and photocatalyst synthesis will significantly contribute to their wider use.

Despite many advantages presented, further research on Co-based MOFs and their composites should primarily focus on improving their stability in water solutions and under ultraviolet light, thanks to which the possibility of their easy regeneration and multiple reuses will increase. In addition, a deeper understanding of the photocatalytic mechanisms of reactions with Co-based MOFs is needed. Currently, several aspects may be proposed for near future studies to fill in the gaps. For instance, the accurate identification of the amount and type of cobalt species needed to perform the most effective treatment of the metal-organic frameworks for their photocatalytic activity is very important. It is also advisable to carefully study the effect of varied linkers as modifiers on already developed MOFs in order to increase their stability and activity. The generation of a wide range of core-shell structures can contribute to reducing the photocorrosion effect. It has been shown that replacing the linker on the surface of MOFs or creating core-shell structures of a certain thickness can significantly alter their photocatalytic properties. Therefore, it is worth pursuing efforts to integrate cobalt-based MOFs also with metal oxides, which can additionally yield more stable systems. Moreover, combining implantation strategies with molecular platforms, in addition to obtaining MOFs in the form of films, require further screening. The combination of theoretical calculations with experimental studies will allow for predicting their activity and selectivity in specific photocatalytic processes, which in turn may contribute to the rational design of new, low-cost, and high-performance photocatalysts. 


\begin{abstract}
Author Contributions: Conceptualization, J.G.; writing-original draft preparation, A.E., A.J. and J.G.; writing-review and editing, J.G.; visualization, A.E. and A.J.; supervision, J.G. All authors have read and agreed to the published version of the manuscript.
\end{abstract}

Funding: This research received no external funding.

Conflicts of Interest: The authors declare no conflict of interest.

\title{
References
}

1. Dawood, F.; Anda, M.; Shafiullah, G.M. Hydrogen production for energy: An overview. Int. J. Hydrogen Energy 2020, 45, 3847-3869. [CrossRef]

2. Jain, I.P. Hydrogen the fuel for 21st century. Int. J. Hydrogen Energy 2009, 34, 7368-7378. [CrossRef]

3. De Richter, R.; Ming, T.; Davies, P.; Liu, W.; Caillol, S. Removal of non- $\mathrm{CO}_{2}$ greenhouse gases by large-scale atmospheric solar photocatalysis. Prog. Energy Combust. Sci. 2017, 60, 68-96. [CrossRef]

4. Manan, Z.A.; Mohd Nawi, W.N.R.; Wan Alwi, S.R.; Klemeš, J.J. Advances in Process Integration research for $\mathrm{CO}_{2}$ emission reduction-A review. J. Clean. Prod. 2017, 167, 1-13. [CrossRef]

5. Vasseghian, Y.; Khataee, A.; Dragoi, E.N.; Moradi, M.; Nabavifard, S.; Oliveri Conti, G.; Mousavi Khaneghah, A. Pollutants degradation and power generation by photocatalytic fuel cells: A comprehensive review. Arab. J. Chem. 2020, 13, 8458-8480. [CrossRef]

6. Saeed, M.; Muneer, M.; ul Haq, A.; Akram, N. Photocatalysis: An effective tool for photodegradation of dyes-A review. Environ. Sci. Pollut. Res. 2021, 29, 293-311. [CrossRef]

7. Wang, Q.; Domen, K. Particulate Photocatalysts for Light-Driven Water Splitting: Mechanisms, Challenges, and Design Strategies. Chem. Rev. 2020, 120, 919-985. [CrossRef]

8. Zhao, W.; Chen, Z.; Yang, X.; Qian, X.; Liu, C.; Zhou, D.; Sun, T.; Zhang, M.; Wei, G.; Dissanayake, P.D.; et al. Recent advances in photocatalytic hydrogen evolution with high-performance catalysts without precious metals. Renew. Sustain. Energy Rev. 2020, 132, 110040. [CrossRef]

9. Ismael, M. A review and recent advances in solar-to-hydrogen energy conversion based on photocatalytic water splitting over doped- $\mathrm{TiO}_{2}$ nanoparticles. Sol. Energy 2020, 211, 522-546. [CrossRef]

10. Lin, S.; Huang, H.; Ma, T.; Zhang, Y. Photocatalytic Oxygen Evolution from Water Splitting. Adv. Sci. 2021, 8, 2002458. [CrossRef]

11. White, J.L.; Baruch, M.F.; Pander, J.E.; Hu, Y.; Fortmeyer, I.C.; Park, J.E.; Zhang, T.; Liao, K.; Gu, J.; Yan, Y.; et al. Light-Driven Heterogeneous Reduction of Carbon Dioxide: Photocatalysts and Photoelectrodes. Chem. Rev. 2015, 115, 12888-12935. [CrossRef]

12. $\mathrm{Xu}$, S.; Carter, E.A. Theoretical Insights into Heterogeneous (Photo)electrochemical $\mathrm{CO}_{2}$ Reduction. Chem. Rev. 2019, 119, 6631-6669. [CrossRef]

13. Wenderich, K.; Mul, G. Methods, Mechanism, and Applications of Photodeposition in Photocatalysis: A Review. Chem. Rev. 2016, 116, 14587-14619. [CrossRef] [PubMed]

14. Wuttke, S. Introduction to Reticular Chemistry. Metal-Organic Frameworks and Covalent Organic Frameworks by Omar M. Yaghi, Markus J. Kalmutzki, and Christian S. Diercks.; John Wiley \& Sons: Hoboken, NJ, USA, 2019; Volume 58, ISBN 3527345027.

15. Hwang, J.; Ejsmont, A.; Freund, R.; Goscianska, J.; Schmidt, B.V.K.J.; Wuttke, S. Controlling the morphology of metal-organic frameworks and porous carbon materials: Metal oxides as primary architecture-directing agents. Chem. Soc. Rev. 2020, 49, 3348-3422. [CrossRef] [PubMed]

16. Ejsmont, A.; Andreo, J.; Lanza, A.; Galarda, A.; Macreadie, L.; Wuttke, S.; Canossa, S.; Ploetz, E.; Goscianska, J. Applications of reticular diversity in metal-organic frameworks: An ever-evolving state of the art. Coord. Chem. Rev. 2021, 430, 213655. [CrossRef]

17. Freund, R.; Zaremba, O.; Arnauts, G.; Ameloot, R.; Skorupskii, G.; Dincă, M.; Bavykina, A.; Gascon, J.; Ejsmont, A.; Goscianska, J.; et al. The Current Status of MOF and COF Applications. Angew. Chem. Int. Ed. 2021, 60, 23975-24001. [CrossRef] [PubMed]

18. Furukawa, H.; Cordova, K.E.; O'Keeffe, M.; Yaghi, O.M. The chemistry and applications of metal-organic frameworks. Science 2013, 341, 1230444. [CrossRef]

19. Hao, Y.-C.; Chen, L.-W.; Li, J.; Guo, Y.; Su, X.; Shu, M.; Zhang, Q.; Gao, W.-Y.; Li, S.; Yu, Z.-L.; et al. Metal-organic framework membranes with single-atomic centers for photocatalytic $\mathrm{CO}_{2}$ and $\mathrm{O}_{2}$ reduction. Nat. Commun. 2021, 12, 2682. [CrossRef]

20. Su, Y.; Song, Z.; Zhu, W.; Mu, Q.; Yuan, X.; Lian, Y.; Cheng, H.; Deng, Z.; Chen, M.; Yin, W.; et al. Visible-Light Photocatalytic $\mathrm{CO}_{2}$ Reduction Using Metal-Organic Framework Derived $\mathrm{Ni}(\mathrm{OH})_{2}$ Nanocages: A Synergy from Multiple Light Reflection, Static Charge Transfer, and Oxygen Vacancies. ACS Catal. 2021, 11, 345-354. [CrossRef]

21. Kalaj, M.; Cohen, S.M. Postsynthetic Modification: An Enabling Technology for the Advancement of Metal-Organic Frameworks. ACS Cent. Sci. 2020, 6, 1046-1057. [CrossRef]

22. Ma, S.; Zhou, H.C. A metal-organic framework with entatic metal centers exhibiting high gas adsorption affinity. J. Am. Chem. Soc. 2006, 128, 11734-11735. [CrossRef] [PubMed]

23. Au, V.K.M. Recent Advances in the Use of Metal-Organic Frameworks for Dye Adsorption. Front. Chem. 2020, 8, 708. [CrossRef] [PubMed]

24. Mandade, P. Introduction, basic principles, mechanism, and challenges of photocatalysis. In Handbook of Nanomaterials for Wastewater Treatment; Elsevier: Amsterdam, The Netherlands, 2021; pp. 137-154. 
25. Li, X.; Yu, J.; Gosztola, D.J.; Fry, H.C.; Deria, P. Wavelength-Dependent Energy and Charge Transfer in MOF: A Step toward Artificial Porous Light-Harvesting System. J. Am. Chem. Soc. 2019, 141, 16849-16857. [CrossRef] [PubMed]

26. Xiao, T.; Zhong, W.; Zhou, L.; Xu, L.; Sun, X.Q.; Elmes, R.B.P.; Hu, X.Y.; Wang, L. Artificial light-harvesting systems fabricated by supramolecular host-guest interactions. Chin. Chem. Lett. 2019, 30, 31-36. [CrossRef]

27. Zhao, X.; Song, X.; Li, Y.; Chang, Z.; Chen, L. Targeted Construction of Light-Harvesting Metal-Organic Frameworks Featuring Efficient Host-Guest Energy Transfer. ACS Appl. Mater. Interfaces 2018, 10, 5633-5640. [CrossRef]

28. Whelan, É.; Steuber, F.W.; Gunnlaugsson, T.; Schmitt, W. Tuning photoactive metal-organic frameworks for luminescence and photocatalytic applications. Coord. Chem. Rev. 2021, 437, 213757. [CrossRef]

29. Xiao, J.D.; Jiang, H.L. Metal-Organic Frameworks for Photocatalysis and Photothermal Catalysis. Acc. Chem. Res. 2018, 52, 356-366. [CrossRef]

30. Mandal, S.; Natarajan, S.; Mani, P.; Pankajakshan, A. Post-Synthetic Modification of Metal-Organic Frameworks toward Applications. Adv. Funct. Mater. 2021, 31, 2006291. [CrossRef]

31. Yin, Z.; Wan, S.; Yang, J.; Kurmoo, M.; Zeng, M.-H. Recent advances in post-synthetic modification of metal-organic frameworks: New types and tandem reactions. Coord. Chem. Rev. 2019, 378, 500-512. [CrossRef]

32. Zhong, G.; Liu, D.; Zhang, J. The application of ZIF-67 and its derivatives: Adsorption, separation, electrochemistry and catalysts. J. Mater. Chem. A 2018, 6, 1887-1899. [CrossRef]

33. Chen, H.; Zhang, Z.; Hu, D.; Chen, C.; Zhang, Y.; He, S.; Wang, J. Catalytic ozonation of norfloxacin using $\mathrm{Co}_{3} \mathrm{O}_{4} / \mathrm{C}$ composite derived from ZIF-67 as catalyst. Chemosphere 2021, 265, 129047. [CrossRef]

34. Sayahi, M.H.; Ghomi, M.; Hamad, S.M.; Ganjali, M.R.; Aghazadeh, M.; Mahdavi, M.; Bahadorikhalili, S. Electrochemical synthesis of three-dimensional flower-like $\mathrm{Ni} / \mathrm{Co}-\mathrm{BTC}$ bimetallic organic framework as heterogeneous catalyst for solvent-free and green synthesis of substituted chromeno[4,3-b]quinolones. J. Chin. Chem. Soc. 2021, 68, 620-629. [CrossRef]

35. Wu, Y.; Song, X.; Xu, S.; Zhang, J.; Zhu, Y.; Gao, L.; Xiao, G. 2-Methylimidazole Modified Co-BTC MOF as an Efficient Catalyst for Chemical Fixation of Carbon Dioxide. Catal. Lett. 2019, 149, 2575-2585. [CrossRef]

36. Liu, Q.; Zhang, L.Y.; Bao, Y.M.; Zhang, N.; Zhang, J.Y.; Xing, Y.Y.; Deng, W.; Liu, Z.J. Structures and catalytic oxidative coupling reaction of four Co-MOFs modified with $\mathrm{R}$-isophthalic acid $(\mathrm{R}=\mathrm{H}, \mathrm{OH}$ and $\mathrm{COOH})$ and trigonal ligands. CrystEngComm 2021, 23, 7590-7601. [CrossRef]

37. Yang, M.X.; Chen, L.J.; Ye, Y.Z.; Lin, X.Y.; Lin, S. Four 3D Co(ii) MOFs based on 2,4,6-tris(4-pyridyl)-1,3,5-triazine and polycarboxylic acid ligands and their derivatives as efficient electrocatalysts for oxygen reduction reaction. Dalt. Trans. 2021, 50, 4904-4913. [CrossRef]

38. Huang, C.; Gu, X.; Su, X.; Xu, Z.; Liu, R.; Zhu, H. Controllable synthesis of Co-MOF-74 catalysts and their application in catalytic oxidation of toluene. J. Solid State Chem. 2020, 289, 121497. [CrossRef]

39. Dhakshinamoorthy, A.; Lanzuela, E.M.; Navalon, S.; Garcia, H. Cobalt-based metal organic frameworks as solids catalysts for oxidation reactions. Catalysts 2021, 11, 95. [CrossRef]

40. Sun, K.K.; Sun, J.L.; Lu, G.P.; Cai, C. Enhanced catalytic activity of cobalt nanoparticles encapsulated with an N-doped porous carbon shell derived from hollow ZIF-8 for efficient synthesis of nitriles from primary alcohols in water. Green Chem. 2019, 21, 4334-4340. [CrossRef]

41. Shen, K.; Chen, X.; Chen, J.; Li, Y. Development of MOF-Derived Carbon-Based Nanomaterials for Efficient Catalysis. ACS Catal. 2016, 6, 5887-5903. [CrossRef]

42. Jagadeesh, R.V.; Murugesan, K.; Alshammari, A.S.; Neumann, H.; Pohl, M.M.; Radnik, J.; Beller, M. MOF-derived cobalt nanoparticles catalyze a general synthesis of amines. Science 2017, 358, 326-332. [CrossRef]

43. Zhang, M.; Xiao, C.; Zhang, C.; Qi, J.; Wang, C.; Sun, X.; Wang, L.; Xu, Q.; Li, J. Large-Scale Synthesis of Biomass@MOF-Derived Porous Carbon/Cobalt Nanofiber for Environmental Remediation by Advanced Oxidation Processes. ACS ESET Eng. 2021, 1, 249-260. [CrossRef]

44. Phillips, C. Cobalt MOF-5: A Novel Catalyst for $\mathrm{CO}_{2}$ Conversion to Carbonates; University of Louisville: Louisville, KY, USA, 2012.

45. Xu, Y.; Zhang, F.; Sheng, T.; Ye, T.; Yi, D.; Yang, Y.; Liu, S.; Wang, X.; Yao, J. Clarifying the controversial catalytic active sites of $\mathrm{Co}_{3} \mathrm{O}_{4}$ for the oxygen evolution reaction. J. Mater. Chem. A 2019, 7, 23191-23198. [CrossRef]

46. Artero, V.; Chavarot-Kerlidou, M.; Fontecave, M. Splitting water with cobalt. Angew. Chem. Int. Ed. 2011, 50, 7238-7266. [CrossRef]

47. Natali, M.; Luisa, A.; Iengo, E.; Scandola, F. Efficient photocatalytic hydrogen generation from water by a cationic cobalt (II) porphyrin. Chem. Commun. 2014, 50, 1842-1844. [CrossRef] [PubMed]

48. Zhang, W.; Huang, R.; Song, L.; Shi, X. Cobalt-based metal-organic frameworks for the photocatalytic reduction of carbon dioxide. Nanoscale 2021, 13, 9075-9090. [CrossRef] [PubMed]

49. Maeda, K.; Domen, K. Photocatalytic water splitting: Recent progress and future challenges. J. Phys. Chem. Lett. 2010, 1, 2655-2661. [CrossRef]

50. Ali, M.; Pervaiz, E.; Noor, T.; Rabi, O.; Zahra, R.; Yang, M. Recent advancements in MOF-based catalysts for applications in electrochemical and photoelectrochemical water splitting: A review. Int. J. Energy Res. 2021, 45, 1190-1226. [CrossRef]

51. Shi, Y.; Yang, A.-F.; Cao, C.-S.; Zhao, B. Applications of MOFs: Recent advances in photocatalytic hydrogen production from water. Coord. Chem. Rev. 2019, 390, 50-75. [CrossRef] 
52. Tasleem, S.; Tahir, M.; Khalifa, W.A. Current trends in structural development and modification strategies for metal-organic frameworks (MOFs) towards photocatalytic $\mathrm{H}_{2}$ production: A review. Int. J. Hydrogen Energy 2021, 46, 14148-14189. [CrossRef]

53. Dhakshinamoorthy, A.; Asiri, A.M.; García, H. Metal-Organic Framework (MOF) Compounds: Photocatalysts for Redox Reactions and Solar Fuel Production. Angew. Chem. Int. Ed. 2016, 55, 5414-5445. [CrossRef]

54. Li, X.; Zhu, Q.L. MOF-based materials for photo- and electrocatalytic $\mathrm{CO}_{2}$ reduction. EnergyChem 2020, 2, 100033. [CrossRef]

55. Liu, C.; Wang, W.; Liu, B.; Qiao, J.; Lv, L.; Gao, X.; Zhang, X.; Xu, D.; Liu, W.; Liu, J.; et al. Recent advances in MOF-based nanocatalysts for photo-promoted $\mathrm{CO}_{2}$ reduction applications. Catalysts 2019, 9, 658. [CrossRef]

56. Gautam, S.; Agrawal, H.; Thakur, M.; Akbari, A.; Sharda, H.; Kaur, R.; Amini, M. Metal oxides and metal organic frameworks for the photocatalytic degradation: A review. J. Environ. Chem. Eng. 2020, 8, 103726. [CrossRef]

57. Belousov, A.S.; Suleimanov, E.V. Application of metal-organic frameworks as an alternative to metal oxide-based photocatalysts for the production of industrially important organic chemicals. Green Chem. 2021, 23, 6172-6204. [CrossRef]

58. Wang, Q.; Gao, Q.; Al-Enizi, A.M.; Nafady, A.; Ma, S. Recent advances in MOF-based photocatalysis: Environmental remediation under visible light. Inorg. Chem. Front. 2020, 7, 300-339. [CrossRef]

59. Melchionna, M.; Fornasiero, P. Updates on the Roadmap for Photocatalysis. ACS Catal. 2020, 10, 5493-5501. [CrossRef]

60. Xu, Y.-J. Promises and Challenges in Photocatalysis. Front. Catal. 2021, 1, 6. [CrossRef]

61. Liu, H.; Zhang, J.; Lu, M.; Liang, L.; Zhang, H.; Wei, J. Biosynthesis based membrane filtration coupled with iron nanoparticles reduction process in removal of dyes. Chem. Eng. J. 2020, 387, 124202. [CrossRef]

62. Joseph, J.; Radhakrishnan, R.C.; Johnson, J.K.; Joy, S.P.; Thomas, J. Ion-exchange mediated removal of cationic dye-stuffs from water using ammonium phosphomolybdate. Mater. Chem. Phys. 2020, 242, 122488. [CrossRef]

63. Goscianska, J.; Ciesielczyk, F. Lanthanum enriched aminosilane-grafted mesoporous carbon material for efficient adsorption of tartrazine azo dye. Microporous Mesoporous Mater. 2019, 280, 7-19. [CrossRef]

64. Ghuge, S.P.; Saroha, A.K. Catalytic ozonation of dye industry effluent using mesoporous bimetallic Ru-Cu/SBA-15 catalyst. Process Saf. Environ. Prot. 2018, 118, 125-132. [CrossRef]

65. Shiva Shankar, Y.; Ankur, K.; Bhushan, P.; Mohan, D. Utilization of Water Treatment Plant (WTP) Sludge for Pretreatment of Dye Wastewater Using Coagulation/Flocculation. In Advances in Waste Management; Springer: Singapore, 2019; pp. 107-121.

66. Golmohammadi, M.; Honarmand, M.; Ghanbari, S. A green approach to synthesis of ZnO nanoparticles using jujube fruit extract and their application in photocatalytic degradation of organic dyes. Spectrochim. Acta Part A Mol. Biomol. Spectrosc. 2020, 229, 117961. [CrossRef] [PubMed]

67. Anwer, H.; Mahmood, A.; Lee, J.; Kim, K.-H.; Park, J.-W.; Yip, A.C.K. Photocatalysts for degradation of dyes in industrial effluents: Opportunities and challenges. Nano Res. 2019, 12, 955-972. [CrossRef]

68. Reddy, C.V.; Reddy, K.R.; Harish, V.V.N.; Shim, J.; Shankar, M.V.; Shetti, N.P.; Aminabhavi, T.M. Metal-organic frameworks (MOFs)-based efficient heterogeneous photocatalysts: Synthesis, properties and its applications in photocatalytic hydrogen generation, $\mathrm{CO}_{2}$ reduction and photodegradation of organic dyes. Int. J. Hydrogen Energy 2020, 45, 7656-7679. [CrossRef]

69. Rafiq, A.; Ikram, M.; Ali, S.; Niaz, F.; Khan, M.; Khan, Q.; Maqbool, M. Photocatalytic degradation of dyes using semiconductor photocatalysts to clean industrial water pollution. J. Ind. Eng. Chem. 2021, 97, 111-128. [CrossRef]

70. Tran, N.T.; Trung, L.G.; Nguyen, M.K. The degradation of organic dye contaminants in wastewater and solution from highly visible light responsive ZIF-67 monodisperse photocatalyst. J. Solid State Chem. 2021, 300, 122287. [CrossRef]

71. Yuan, C.; Cheng, P.; Li, J.; Gao, X.; Gao, X.; Wang, X.; Jin, M.; Nötzel, R.; Zhou, G.; Zhang, Z.; et al. ZIF-67 with Argon annealing treatment for visible light responsive degradation of organic dyes in a wide $\mathrm{pH}$ range. Microporous Mesoporous Mater. 2019, 285, 13-20. [CrossRef]

72. Flihh, S.M.; Ammar, S.H. Fabrication and photocatalytic degradation activity of core/shell ZIF-67@CoWO $@_{4} \mathrm{CoS}_{\text {heterostructure }}$ photocatalysts under visible light. Environ. Nanotechnol. Monit. Manag. 2021, 16, 100595. [CrossRef]

73. Nguyen, T.N.; Nguyen, H.P.; Kim, T.H.; Lee, S.W. Bimetallic Co/Zn-ZIF as an efficient photocatalyst for degradation of indigo carmine. Korean J. Mater. Res. 2018, 28, 68-74. [CrossRef]

74. Cui, G.; Liu, W.; Wang, L.; Wu, R.; Bi, C.; Zhang, D.; Fan, Y. Two novel Co (II) bifunctional MOFs: Syntheses and applications in photocatalytic degradation of dyes and electrocatalytic water oxidation. J. Solid State Chem. 2021, 304, 122562. [CrossRef]

75. Zhang, X.; Meng, X.; Wang, J.; Ji, Z.; Lu, P.; Wang, X.; Chen, F. Rational design of two novel metal-organic frameworks as photocatalysts for degradation of organic dyes and their derived materials as electrocatalysts for OER. Inorg. Chim. Acta 2021, 523, 120416. [CrossRef]

76. Wang, J.; Zhou, S.; Chen, C.; Lu, L.; Li, B.; Hu, W.; Kumar, A.; Muddassir, M. Two new uncommon 3D cobalt-based metal organic frameworks: Temperature induced syntheses and enhanced photocatalytic properties against aromatic dyes. Dye. Pigment. 2021, 187, 109068. [CrossRef]

77. Yang, Y.; Fu, P.; Li, X.; Su, Z.M.; Xu, N.; Wang, X. long Co-based MOF for efficient degradation of RB in aqueous solutions by peroxymonosulfate activation. Inorg. Chem. Commun. 2020, 122, 108282. [CrossRef]

78. Wu, R.; Bi, C.; Zhang, X.; Wang, J.; Wang, L.; Fan, C.; Wang, M.; Shao, F.; Li, N.; Zong, Z.; et al. Construction of two cobalt based bi-functional metal-organic frameworks for enhancing electrocatalytic water oxidation and photocatalytic disposals of hazardous aromatic dyes. Mol. Catal. 2021, 505, 111450. [CrossRef] 
79. El-Fawal, E.M.; Abd El Salam, H.M. Deposition of dyes on Cobalt-based metal-organic framework (Co-MOF) composites with promoted achievement photocatalytic degradation of an anionic dye (EBT) under visible light irradiation. Int. J. Environ. Anal. Chem. 2020. [CrossRef]

80. Li, J.X.; Qin, Z.B.; Li, Y.H.; Cui, G.H. Visible-light-driven photocatalyst for the degradation of methylene blue over a 3D cobalt(II)-4,4'-oxybis(benzoate) framework. Inorg. Chem. Commun. 2018, 90, 112-114. [CrossRef]

81. Chen, J.; Xing, Z.; Han, J.; Su, M.; Li, Y.; Lu, A. Enhanced degradation of dyes by Cu-Co-Ni nanoparticles loaded on aminomodified octahedral metal-organic framework. J. Alloys Compd. 2020, 834, 155106. [CrossRef]

82. Guo, X.; Liu, L.; Xiao, Y.; Mehmood, R.; Xiao, Y.; Qi, Y.; Zhang, F. Water-Stable Cobalt-Based MOF for Water Oxidation in Neutral Aqueous Solution: A Case of Mimicking the Photosystem II. Inorg. Chem. 2021, 60, 1790-1796. [CrossRef] [PubMed]

83. Hernández-Alonso, M.D.; Fresno, F.; Suárez, S.; Coronado, J.M. Development of alternative photocatalysts to TiO ${ }_{2}$ : Challenges and opportunities. Energy Environ. Sci. 2009, 2, 1231-1257. [CrossRef]

84. Huang, G.-F.; Ma, Z.-L.; Huang, W.-Q.; Tian, Y.; Jiao, C.; Yang, Z.-M.; Wan, Z.; Pan, A. Semiconductor Photocatalyst: Possibilities and Challenges. J. Nanomater. 2013, 2013, 371356. [CrossRef]

85. Yemmireddy, V.K.; Hung, Y.-C. Using Photocatalyst Metal Oxides as Antimicrobial Surface Coatings to Ensure Food SafetyOpportunities and Challenges. Compr. Rev. Food Sci. Food Saf. 2017, 16, 617-631. [CrossRef]

86. Sohrabi, S.; Keshavarz Moraveji, M.; Iranshahi, D. A review on the design and development of photocatalyst synthesis and application in microfluidic reactors: Challenges and opportunities. Rev. Chem. Eng. 2020, 36, 687-722. [CrossRef]

87. Kallawar, G.A.; Barai, D.P.; Bhanvase, B.A. Bismuth titanate based photocatalysts for degradation of persistent organic compounds in wastewater: A comprehensive review on synthesis methods, performance as photocatalyst and challenges. J. Clean. Prod. 2021, 318, 128563. [CrossRef]

88. Chen, S.; Huang, D.; Xu, P.; Xue, W.; Lei, L.; Cheng, M.; Wang, R.; Liu, X.; Deng, R. Semiconductor-based photocatalysts for photocatalytic and photoelectrochemical water splitting: Will we stop with photocorrosion? J. Mater. Chem. A 2020, 8, 2286-2322 [CrossRef]

89. Liu, B.; Li, J.; Wu, H.-L.; Liu, W.-Q.; Jiang, X.; Li, Z.-J.; Chen, B.; Tung, C.-H.; Wu, L.-Z. Improved Photoelectrocatalytic Performance for Water Oxidation by Earth-Abundant Cobalt Molecular Porphyrin Complex-Integrated BiVO 4 Photoanode. ACS Appl. Mater. Interfaces 2016, 8, 18577-18583. [CrossRef]

90. Soni, V.; Xia, C.; Cheng, C.K.; Nguyen, V.-H.; Nguyen, D.L.T.; Bajpai, A.; Kim, S.Y.; Van Le, Q.; Khan, A.A.P.; Singh, P.; et al Advances and recent trends in cobalt-based cocatalysts for solar-to-fuel conversion. Appl. Mater. Today 2021, 24, 101074. [CrossRef]

91. Maeda, K.; Ishimaki, K.; Tokunaga, Y.; Lu, D.; Eguchi, M. Modification of Wide-Band-Gap Oxide Semiconductors with Cobalt Hydroxide Nanoclusters for Visible-Light Water Oxidation. Angew. Chem. Int. Ed. 2016, 55, 8309-8313. [CrossRef]

92. Maity, K.; Bhunia, K.; Pradhan, D.; Biradha, K. Co(II)-Doped Cd-MOF as an Efficient Water Oxidation Catalyst: Doubly Interpenetrated Boron Nitride Network with the Encapsulation of Free Ligand Containing Pyridine Moieties. ACS Appl. Mater. Interfaces 2017, 9, 37548-37553. [CrossRef] [PubMed]

93. Wang, C.; Xie, Z.; Dekrafft, K.E.; Lin, W. Doping metal-organic frameworks for water oxidation, carbon dioxide reduction, and organic photocatalysis. J. Am. Chem. Soc. 2011, 133, 13445-13454. [CrossRef] [PubMed]

94. Lionet, Z.; Kim, T.-H.; Horiuchi, Y.; Lee, S.W.; Matsuoka, M. Linker Engineering of Iron-Based MOFs for Efficient Visible-LightDriven Water Oxidation Reaction. J. Phys. Chem. C 2019, 123, 27501-27508. [CrossRef]

95. Dong, Y.-J.; Liao, J.-F.; Kong, Z.-C.; Xu, Y.-F.; Chen, Z.-J.; Chen, H.-Y.; Kuang, D.-B.; Fenske, D.; Su, C.-Y. Conformal coating of ultrathin metal-organic framework on semiconductor electrode for boosted photoelectrochemical water oxidation. Appl. Catal. B Environ. 2018, 237, 9-17. [CrossRef]

96. Younus, H.A.; Ahmad, N.; Chughtai, A.H.; Vandichel, M.; Busch, M.; Van Hecke, K.; Yusubov, M.; Song, S.; Verpoort, F. A Robust Molecular Catalyst Generated In Situ for Photo- and Electrochemical Water Oxidation. ChemSusChem 2017, 10, 862-875. [CrossRef]

97. Hong, D.; Jung, J.; Park, J.; Yamada, Y.; Suenobu, T.; Lee, Y.M.; Nam, W.; Fukuzumi, S. Water-soluble mononuclear cobalt complexes with organic ligands acting as precatalysts for efficient photocatalytic water oxidation. Energy Environ. Sci. 2012, 5, 7606-7616. [CrossRef]

98. Liu, S.; Lei, Y.J.; Xin, Z.J.; Xiang, R.J.; Styring, S.; Thapper, A.; Wang, H.Y. Ligand modification to stabilize the cobalt complexes for water oxidation. Int. J. Hydrogen Energy 2017, 42, 29716-29724. [CrossRef]

99. Luo, H.; Zeng, Z.; Zeng, G.; Zhang, C.; Xiao, R.; Huang, D.; Lai, C.; Cheng, M.; Wang, W.; Xiong, W.; et al. Recent progress on metal-organic frameworks based- and derived-photocatalysts for water splitting. Chem. Eng. J. 2020, 383, 123196. [CrossRef]

100. Huang, N.Y.; Shen, J.Q.; Ye, Z.M.; Zhang, W.X.; Liao, P.Q.; Chen, X.M. An exceptionally stable octacobalt-cluster-based metalorganic framework for enhanced water oxidation catalysis. Chem. Sci. 2019, 10, 9859-9864. [CrossRef] [PubMed]

101. Shah, W.A.; Waseem, A.; Nadeem, M.A.; Kögerler, P. Leaching-free encapsulation of cobalt-polyoxotungstates in MIL-100 (Fe) for highly reproducible photocatalytic water oxidation. Appl. Catal. A Gen. 2018, 567, 132-138. [CrossRef]

102. Han, J.; Wang, D.; Du, Y.; Xi, S.; Hong, J.; Yin, S.; Chen, Z.; Zhou, T.; Xu, R. Metal-organic framework immobilized cobalt oxide nanoparticles for efficient photocatalytic water oxidation. J. Mater. Chem. A 2015, 3, 20607-20613. [CrossRef]

103. Paille, G.; Gomez-Mingot, M.; Roch-Marchal, C.; Lassalle-Kaiser, B.; Mialane, P.; Fontecave, M.; Mellot-Draznieks, C.; Dolbecq, A. A Fully Noble Metal-Free Photosystem Based on Cobalt-Polyoxometalates Immobilized in a Porphyrinic Metal-Organic Framework for Water Oxidation. J. Am. Chem. Soc. 2018, 140, 3613-3618. [CrossRef] [PubMed] 
104. Paille, G.; Gomez-Mingot, M.; Roch-Marchal, C.; Haouas, M.; Benseghir, Y.; Pino, T.; Ha-Thi, M.H.; Landrot, G.; Mialane, P.; Fontecave, M.; et al. Thin Films of Fully Noble Metal-Free POM@MOF for Photocatalytic Water Oxidation. ACS Appl. Mater. Interfaces 2019, 11, 47837-47845. [CrossRef]

105. Guo, C.; Guo, J.; Zhang, Y.; Wang, D.; Zhang, L.; Guo, Y.; Ma, W.; Wang, J. Synthesis of core-shell ZIF-67@Co-MOF-74 catalyst with controllable shell thickness and enhanced photocatalytic activity for visible light-driven water oxidation. CrystEngComm 2018, 20, 7659-7665. [CrossRef]

106. Xu, Q.; Li, H.; Yue, F.; Chi, L.; Wang, J. Nanoscale cobalt metal-organic framework as a catalyst for visible light-driven and electrocatalytic water oxidation. New J. Chem. 2016, 40, 3032-3035. [CrossRef]

107. Saliba, D.; Ammar, M.; Rammal, M.; Al-Ghoul, M.; Hmadeh, M. Crystal Growth of ZIF-8, ZIF-67, and Their Mixed-Metal Derivatives. J. Am. Chem. Soc. 2018, 140, 1812-1823. [CrossRef]

108. Sankar, S.S.; Karthick, K.; Sangeetha, K.; Kundu, S. In Situ Modified Nitrogen-Enriched ZIF-67 Incorporated ZIF-7 Nanofiber: An Unusual Electrocatalyst for Water Oxidation. Inorg. Chem. 2019, 58, 13826-13835. [CrossRef] [PubMed]

109. Feng, S.; Bu, M.; Pang, J.; Fan, W.; Fan, L.; Zhao, H.; Yang, G.; Guo, H.; Kong, G.; Sun, H.; et al. Hydrothermal stable ZIF-67 nanosheets via morphology regulation strategy to construct mixed-matrix membrane for gas separation. J. Memb. Sci. 2020, 593, 117404. [CrossRef]

110. Qian, X.; Ren, Q.; Wu, X.; Sun, J.; Wu, H.; Lei, J. Enhanced Water Stability in Zn-Doped Zeolitic Imidazolate Framework-67 (ZIF-67) for $\mathrm{CO}_{2}$ Capture Applications. ChemistrySelect 2018, 3, 657-661. [CrossRef]

111. Zhang, Q.; Wang, H.; Dong, Y.; Yan, J.; Ke, X.; Wu, Q.; Xue, S. In situ growth of ultrathin Co-MOF nanosheets on A-Fe $\mathrm{O}_{3}$ hematite nanorods for efficient photoelectrochemical water oxidation. Sol. Energy 2018, 171, 388-396. [CrossRef]

112. Dong, Y.; Tian, T.; Xu, C.; Ma, K.; Sun, W.; Ding, Y. Cubic Co-Co prussian blue MOF-based transition metal phosphide as an efficient catalyst for visible light-driven water oxidation. J. Catal. 2020, 382, 13-21. [CrossRef]

113. Schneider, J.T.; Firak, D.S.; Ribeiro, R.R.; Peralta-Zamora, P. Use of scavenger agents in heterogeneous photocatalysis: Truths, half-truths, and misinterpretations. Phys. Chem. Chem. Phys. 2020, 22, 15723-15733. [CrossRef]

114. Chen, Z.Y.; Long, Z.H.; Wang, X.Z.; Zhou, J.Y.; Wang, X.S.; Zhou, X.P.; Li, D. Cobalt-Based Metal-Organic Cages for Visible-LightDriven Water Oxidation. Inorg. Chem. 2021, 60, 10380-10386. [CrossRef]

115. Fajrina, N.; Tahir, M. A critical review in strategies to improve photocatalytic water splitting towards hydrogen production. Int. J. Hydrogen Energy 2019, 44, 540-577. [CrossRef]

116. Yang, J.; Wang, D.; Han, H.; Li, C. Roles of cocatalysts in photocatalysis and photoelectrocatalysis. Acc. Chem. Res. 2013, 46, 1900-1909. [CrossRef]

117. Takata, T.; Jiang, J.; Sakata, Y.; Nakabayashi, M.; Shibata, N.; Nandal, V.; Seki, K.; Hisatomi, T.; Domen, K. Photocatalytic water splitting with a quantum efficiency of almost unity. Nature 2020, 581, 411-414. [CrossRef]

118. Liu, S.; Zhang, C.; Sun, Y.; Chen, Q.; He, L.; Zhang, K.; Zhang, J.; Liu, B.; Chen, L.-F. Design of metal-organic framework-based photocatalysts for hydrogen generation. Coord. Chem. Rev. 2020, 413, 213266. [CrossRef]

119. Alvaro, M.; Carbonell, E.; Ferrer, B.; Llabrés i Xamena, F.X.; Garcia, H. Semiconductor behavior of a metal-organic framework (MOF). Chem. Eur. J. 2007, 13, 5106-5112. [CrossRef] [PubMed]

120. Xia, B.; Ran, J.; Chen, S.; Song, L.; Zhang, X.; Jing, L.; Qiao, S.-Z. A two-dimensional metal-organic framework accelerating visible-light-driven $\mathrm{H}_{2}$ production. Nanoscale 2019, 11, 8304-8309. [CrossRef] [PubMed]

121. Tian, J.-W.; Wu, Y.-P.; Li, Y.-S.; Wei, J.-H.; Yi, J.-W.; Li, S.; Zhao, J.; Li, D.-S. Integration of semiconductor oxide and a microporous $(3,10)$-connected $\mathrm{Co}_{6}$-based metal-organic framework for enhanced oxygen evolution reaction. Inorg. Chem. 2019, 58, 5837-5843. [CrossRef]

122. Hu, L.; Hu, Y.; Liu, R.; Mao, Y.; Balogun, M.-S.; Jie, T.; Tong, Y. Co-based MOF-derived Co/CoN $/ \mathrm{Co}_{2} \mathrm{P}$ ternary composite embedded in $\mathrm{N}$ - and P-doped carbon as bifunctional nanocatalysts for efficient overall water splitting. Int. J. Hydrogen Energy 2019, 44, 11402-11410. [CrossRef]

123. Cai, X.; Zeng, Z.; Liu, Y.; Li, Z.; Gu, X.; Zhao, Y.; Mao, L.; Zhang, J. Visible-light-driven water splitting by yolk-shelled ZnIn2S4-based heterostructure without noble-metal co-catalyst and sacrificial agent. Appl. Catal. B Environ. 2021, $297,120391$. [CrossRef]

124. Yang, S.; Pattengale, B.; Kovrigin, E.L.; Huang, J. Photoactive Zeolitic Imidazolate Framework as Intrinsic Heterogeneous Catalysts for Light-Driven Hydrogen Generation. ACS Energy Lett. 2017, 2, 75-80. [CrossRef]

125. Li, Y.; Jin, Z.; Zhao, T. Performance of ZIF-67-Derived fold polyhedrons for enhanced photocatalytic hydrogen evolution. Chem. Eng. J. 2020, 382, 123051. [CrossRef]

126. Nasalevich, M.A.; Becker, R.; Ramos-Fernandez, E.V.; Castellanos, S.; Veber, S.L.; Fedin, M.V.; Kapteijn, F.; Reek, J.N.H.; van der Vlugt, J.I.; Gascon, J. Co@ $\mathrm{NH}_{2}$-MIL-125(Ti): Cobaloxime-derived metal-organic framework-based composite for light-driven $\mathrm{H}_{2}$ production. Energy Environ. Sci. 2015, 8, 364-375. [CrossRef]

127. Yang, G.L.; Che, X.J.; Hou, S.L.; Cao, C.S.; Zhao, B. Photocatalytic Hydrogen Evolution Based on Cobalt-Organic Framework with High Water Vapor Adsorption. Inorg. Chem. 2021, 60, 1922-1929. [CrossRef] [PubMed]

128. Huo, D.; Lin, F.; Chen, S.; Ni, Y.; Wang, R.; Chen, H.; Duan, L.; Ji, Y.; Zhou, A.; Tong, L. Ruthenium Complex-Incorporated Two-Dimensional Metal-Organic Frameworks for Cocatalyst-Free Photocatalytic Proton Reduction from Water. Inorg. Chem. 2020, 59, 2379-2386. [CrossRef] [PubMed] 
129. Kumar, D.P.; Park, H.; Kim, E.H.; Hong, S.; Gopannagari, M.; Reddy, D.A.; Kim, T.K. Noble metal-free metal-organic frameworkderived onion slice-type hollow cobalt sulfide nanostructures: Enhanced activity of CdS for improving photocatalytic hydrogen production. Appl. Catal. B Environ. 2018, 224, 230-238. [CrossRef]

130. Mikhaylov, A.; Moiseev, N.; Aleshin, K.; Burkhardt, T. Global climate change and greenhouse effect. Entrep. Sustain. Issues 2020, 7, 2897-2913. [CrossRef]

131. Qiao, H.; Zheng, F.; Jiang, H.; Dong, K. The greenhouse effect of the agriculture-economic growth-renewable energy nexus: Evidence from G20 countries. Sci. Total Environ. 2019, 671, 722-731. [CrossRef] [PubMed]

132. Adams, S.; Nsiah, C. Reducing carbon dioxide emissions; Does renewable energy matter? Sci. Total Environ. 2019, 693, 133288. [CrossRef]

133. Allen, M.R.; Stocker, T.F. Impact of delay in reducing carbon dioxide emissions. Nat. Clim. Chang. 2014, 4, 23-26. [CrossRef]

134. Yang, H.; Gan, T.; Liang, W.; Liao, X. Can policies aimed at reducing carbon dioxide emissions help mitigate haze pollution? An empirical analysis of the emissions trading system. Environ. Dev. Sustain. 2021,1-22. [CrossRef]

135. Chen, C.; Khosrowabadi Kotyk, J.F.; Sheehan, S.W. Progress toward Commercial Application of Electrochemical Carbon Dioxide Reduction. Chem 2018, 4, 2571-2586. [CrossRef]

136. He, J.; Janáky, C. Recent Advances in Solar-Driven Carbon Dioxide Conversion: Expectations versus Reality. ACS Energy Lett. 2020, 5, 1996-2014. [CrossRef]

137. Soni, D.; Parsoya, P.; Menariya, B.K.; Vyas, R.; Ameta, R. Photoelectrochemical cells. In Solar Energy Conversion and Storage: Photochemical Modes; Elsevier: Amsterdam, The Netherlands, 2015; pp. 29-53. ISBN 9781482246315.

138. Fu, J.; Jiang, K.; Qiu, X.; Yu, J.; Liu, M. Product selectivity of photocatalytic $\mathrm{CO}_{2}$ reduction reactions. Mater. Today 2020, 32, $222-243$. [CrossRef]

139. Mishra, B.; Chaudhary, Y.S. Photocatalytic $\mathrm{CO}_{2}$ reduction to fuels. Sol. Fuel Gener. 2017, 10, 141-162. [CrossRef]

140. Avci, G.; Erucar, I.; Keskin, S. Do New MOFs Perform Better for $\mathrm{CO}_{2}$ Capture and $\mathrm{H}_{2}$ Purification? Computational Screening of the Updated MOF Database. ACS Appl. Mater. Interfaces 2020, 12, 41567-41579. [CrossRef]

141. Li, D.; Kassymova, M.; Cai, X.; Zang, S.-Q.; Jiang, H.-L. Photocatalytic $\mathrm{CO}_{2}$ reduction over metal-organic framework-based materials. Coord. Chem. Rev. 2020, 412, 213262. [CrossRef]

142. Scatena, R.; Guntern, Y.T.; Macchi, P. Electron Density and Dielectric Properties of Highly Porous MOFs: Binding and Mobility of Guest Molecules in $\mathrm{Cu}_{3}(\mathrm{BTC})_{2}$ and $\mathrm{Zn}_{3}(\mathrm{BTC})_{2}$. J. Am. Chem. Soc. 2019, 141, 9382-9390. [CrossRef]

143. Hoch, L.B.; Szymanski, P.; Ghuman, K.K.; He, L.; Liao, K.; Qiao, Q.; Reyes, L.M.; Zhu, Y.; El-Sayed, M.A.; Singh, C.V. Carrier dynamics and the role of surface defects: Designing a photocatalyst for gas-phase $\mathrm{CO}_{2}$ reduction. Proc. Natl. Acad. Sci. USA 2016, 113, E8011-E8020. [CrossRef] [PubMed]

144. Wang, J.W.; Huang, H.H.; Sun, J.K.; Ouyang, T.; Zhong, D.C.; Lu, T.B. Electrocatalytic and Photocatalytic Reduction of $\mathrm{CO}_{2}$ to CO by Cobalt(II) Tripodal Complexes: Low Overpotentials, High Efficiency and Selectivity. ChemSusChem 2018, 11, $1025-1031$. [CrossRef]

145. Wang, F.; Cao, B.; To, W.P.; Tse, C.W.; Li, K.; Chang, X.Y.; Zang, C.; Chan, S.L.F.; Che, C.M. The effects of chelating N4 ligand coordination on $\mathrm{Co}(\mathrm{II})$-catalysed photochemical conversion of $\mathrm{CO}_{2}$ to $\mathrm{CO}$ : Reaction mechanism and DFT calculations. Catal. Sci. Technol. 2016, 6, 7408-7420. [CrossRef]

146. Cho, H.Y.; Yang, D.A.; Kim, J.; Jeong, S.Y.; Ahn, W.S. $\mathrm{CO}_{2}$ adsorption and catalytic application of Co-MOF-74 synthesized by microwave heating. Catal. Today 2012, 185, 35-40. [CrossRef]

147. Wang, Y.; Huang, N.Y.; Shen, J.Q.; Liao, P.Q.; Chen, X.M.; Zhang, J.P. Hydroxide Ligands Cooperate with Catalytic Centers in Metal-Organic Frameworks for Efficient Photocatalytic $\mathrm{CO}_{2}$ Reduction. J. Am. Chem. Soc. 2018, 140, 38-41. [CrossRef]

148. Ye, L.; Gao, Y.; Cao, S.; Chen, H.; Yao, Y.; Hou, J.; Sun, L. Assembly of highly efficient photocatalytic $\mathrm{CO}_{2}$ conversion systems with ultrathin two-dimensional metal-organic framework nanosheets. Appl. Catal. B Environ. 2018, 227, 54-60. [CrossRef]

149. Johnson, J.A.; Luo, J.; Zhang, X.; Chen, Y.S.; Morton, M.D.; Echeverría, E.; Torres, F.E.; Zhang, J. Porphyrin-Metalation-Mediated Tuning of Photoredox Catalytic Properties in Metal-Organic Frameworks. ACS Catal. 2015, 5, 5283-5291. [CrossRef]

150. Xu, J.; Liu, X.; Zhou, Z.; Xu, M. Photocatalytic $\mathrm{CO}_{2}$ reduction catalyzed by metalloporphyrin: Understanding of cobalt and nickel sites in activity and adsorption. Appl. Surf. Sci. 2020, 513, 145801. [CrossRef]

151. Zhang, H.; Wei, J.; Dong, J.; Liu, G.; Shi, L.; An, P.; Zhao, G.; Kong, J.; Wang, X.; Meng, X.; et al. Efficient Visible-Light-Driven Carbon Dioxide Reduction by a Single-Atom Implanted Metal-Organic Framework. Angew. Chem. 2016, 128, 14522-14526. [CrossRef]

152. Wang, S.; Yao, W.; Lin, J.; Ding, Z.; Wang, X. Cobalt imidazolate metal-organic frameworks photosplit $\mathrm{CO}_{2}$ under mild reaction conditions. Angew. Chem. Int. Ed. 2014, 53, 1034-1038. [CrossRef]

153. Wang, S.; Lin, J.; Wang, X. Semiconductor-redox catalysis promoted by metal-organic frameworks for $\mathrm{CO}_{2}$ reduction. Phys. Chem. Chem. Phys. 2014, 16, 14656-14660. [CrossRef]

154. Wang, S.; Wang, X. Photocatalytic $\mathrm{CO}_{2}$ reduction by $\mathrm{CdS}$ promoted with a zeolitic imidazolate framework. Appl. Catal. B Environ. 2015, 162, 494-500. [CrossRef]

155. Zhang, J.; Wang, Y.; Wang, H.; Zhong, D.; Lu, T. Enhancing photocatalytic performance of metal-organic frameworks for $\mathrm{CO}_{2}$ reduction by a bimetallic strategy. Chin. Chem. Lett. 2021. [CrossRef]

156. Zhang, J.H.; Yang, W.; Zhang, M.; Wang, H.J.; Si, R.; Zhong, D.C.; Lu, T.B. Metal-organic layers as a platform for developing single-atom catalysts for photochemical $\mathrm{CO}_{2}$ reduction. Nano Energy 2021, 80, 105542. [CrossRef] 
157. Liao, W.M.; Zhang, J.H.; Wang, Z.; Lu, Y.L.; Yin, S.Y.; Wang, H.P.; Fan, Y.N.; Pan, M.; Su, C.Y. Semiconductive AmineFunctionalized Co(II)-MOF for Visible-Light-Driven Hydrogen Evolution and $\mathrm{CO}_{2}$ Reduction. Inorg. Chem. 2018, 57, 11436-11442. [CrossRef]

158. Qin, J.; Wang, S.; Wang, X. Visible-light reduction $\mathrm{CO}_{2}$ with dodecahedral zeolitic imidazolate framework ZIF-67 as an efficient co-catalyst. Appl. Catal. B Environ. 2017, 209, 476-482. [CrossRef]

159. Wang, H.; Wu, D.; Yang, C.; Lu, H.; Gao, Z.; Xu, F.; Jiang, K. Multi-functional amorphous $\mathrm{TiO}_{2}$ layer on $\mathrm{ZIF}^{-67}$ for enhanced $\mathrm{CO}_{2}$ photoreduction performances under visible light. J. CO2 Util. 2019, 34, 411-421. [CrossRef]

160. Yuan, X.; Mu, Q.; Xue, S.; Su, Y.; Zhu, Y.; Sun, H.; Deng, Z.; Peng, Y. Polypyrrole reinforced ZIF-67 with modulated facet exposure and billion-fold electrical conductivity enhancement towards robust photocatalytic $\mathrm{CO}_{2}$ reduction. J. Energy Chem. 2021, 60, 202-208. [CrossRef]

161. Li, S.; Shan, S.; Chen, S.; Li, H.; Li, Z.; Liang, Y.; Fei, J.; Xie, L.; Li, J. Photocatalytic degradation of hazardous organic pollutants in water by Fe-MOFs and their composites: A review. J. Environ. Chem. Eng. 2021, 9, 105967. [CrossRef]

162. Mohammadinezhad, A.; Akhlaghinia, B. Engineered Superparamagnetic Core-Shell Metal-Organic Frame-Work (Fe $\mathrm{O}_{4} @ \mathrm{Ni}^{-\mathrm{Co}-}$ BTC NPs) with Enhanced Photocatalytic Activity for Selective Aerobic Oxidation of Alcohols under Solar Light Irradiation. Catal. Lett. 2021, 151, 107-123. [CrossRef]

163. Xiong, L.; Tang, J. Strategies and Challenges on Selectivity of Photocatalytic Oxidation of Organic Substances. Adv. Energy Mater. 2021, 11, 2003216. [CrossRef]

164. Zhang, F.; Zhang, J.; Zhang, B.; Zheng, L.; Cheng, X.; Wan, Q.; Han, B.; Zhang, J. Improved catalytic performance of Co-MOF-74 by nanostructure construction. Green Chem. 2020, 22, 5995-6000. [CrossRef]

165. Hosseini, S.M.; Dehghan, H.; Safarifard, V. Enhancement of photocatalytic aerobic oxidation of benzyl alcohol with the incorporation of cobalt in Zn-based MOF via post-synthetic metal exchange. Polyhedron 2022, 212, 115581. [CrossRef]

166. Khosroshahi, N.; Karimi, M.; Taghvaei, T.; Safarifard, V. Ultrasound-assisted synthesis of $\mathrm{CoFe}_{2} \mathrm{O}_{4} / \mathrm{Ce}-\mathrm{UiO}-66$ nanocomposite for photocatalytic aerobic oxidation of aliphatic alcohols. Mater. Today Chem. 2021, 22, 100582. [CrossRef]

167. Hosseini, S.M.; Karimi, M.; Safarifard, V. Metal-organic framework/carbon nitride nanosheets composites (TMU-49/CNNSs): Efficient photocatalyst for aerobic oxidation of alcohols under visible light. New J. Chem. 2021, 45, 17674-17682. [CrossRef] 